Article

\title{
Long-Term Distribution Patterns of Chlorophyll-a Concentration in China's Largest Freshwater Lake: MERIS Full-Resolution Observations with a Practical Approach
}

\section{Lian Feng ${ }^{1,2,3}$, Chuanmin Hu ${ }^{2}$, Xingxing Han ${ }^{1}$, Xiaoling Chen ${ }^{1,3, *}$ and Lin Qi ${ }^{2,4}$}

1 State Key Laboratory of Information Engineering in Surveying, Mapping and Remote Sensing, Wuhan University, Wuhan 430079, China; E-Mails: lian.feng@whu.edu.cn (L.F.); xxhan1989@gmail.com (X.H.)

2 College of Marine Science, University of South Florida, 140 Seventh Avenue South, St. Petersburg, FL 33701, USA; E-Mails: huc@usf.edu (C.H.); 1qi@mail.usf.edu (L.Q.)

3 Collaborative Innovation Center for Geospatial Information Technology, Wuhan University, Wuhan 430079, China

4 State Key Laboratory of Lake Science and Environment, Nanjing Institute of Geography and Limnology, Chinese Academy of Sciences, Nanjing 210008, China

* Author to whom correspondence should be addressed; E-Mail: xiaoling_chen@whu.edu.cn; Tel.: +86-27-6877-9233.

Academic Editors: Deepak Mishra and Prasad S. Thenkabail

Received: 9 October 2014 / Accepted: 15 December 2014 / Published: 29 December 2014

\begin{abstract}
A new empirical Chl-a algorithm has been developed and validated for the largest freshwater lake of China (Poyang Lake) using a normalized green-red difference index (NGRDI), where the uncertainty was estimated to be $<45 \%$ for Chl-a ranging between 1.3 and $10.5 \mathrm{mg} \cdot \mathrm{m}^{-3}$. The combined approach of using the NGRDI algorithm and atmospherically-corrected Medium Resolution Imaging Spectrometer (MERIS) data showed an advantage over other popular approaches. The algorithm was then applied to 325 carefully-selected MERIS full-resolution (300-m) scenes between 2003 and 2012, with pixels of extreme turbidity (NGRDI $<0.06$, corresponding to $>\sim 25 \mathrm{mg} \cdot \mathrm{L}^{-1}$ total suspended sediments or TSS) masked. The long-term Chl-a distribution showed significant spatial gradient and temporal variability, with Chl-a ranging between $2.4 \pm 0.2 \mathrm{mg} \cdot \mathrm{m}^{-3}$ in April and $4.4 \pm 1.0 \mathrm{mg} \cdot \mathrm{m}^{-3}$ in July and no significant increasing or decreasing trend during the 10 -year period. In waters where Chl-a was retrievable (i.e., where TSS is $<25 \mathrm{mg} \cdot \mathrm{L}^{-1}$ ), Chl-a concentration indicated a significant negative correlation with TSS concentration on a
\end{abstract}


seasonal scale and a significant positive correlation with precipitation over the years. Potential eutrophic regions in the southern and eastern lake, thought to be results of limited water exchange with the main lake, were delineated based on the occurrence frequency of high Chl-a $\left(>10 \mathrm{mg} \cdot \mathrm{m}^{-3}\right)$ in summer. The study not only provides, for the first time, synoptic baseline information on the lake's Chl-a distributions and potential eutrophic regions, but also demonstrates a practical approach that might be extended to assess eutrophication conditions in other inland waters.

Keywords: remote sensing; MERIS; chlorophyll-a; Poyang Lake; eutrophication; suspended sediments; SeaDAS; BEAM; atmospheric correction; algorithms

\section{Introduction}

With the rapid development of industrialization and urbanization, dramatic changes have occurred in many inland lakes in China during the past few decades. For example, water impoldering and reclamation in the Central Yangtze Basin have resulted in a rapid decrease in lake number and area in the last century [1]. Extensive water reclamation and dam construction also modulated the hydrological conditions of the lakes in the middle and south of China [2,3]. Compared with changes in water quantity, the problems associated with deteriorated water quality appear more prominent. For example, the exacerbated eutrophication in some large lakes (such as Taihu Lake and Chaohu Lake) has triggered serious ecological and social problems in recent years [4,5].

As the largest freshwater lake in China with a maximum inundation area of $>3000 \mathrm{~km}^{2}$, Poyang Lake is not immune to these changes. The inundation area of Poyang Lake has been decreased in recent years, possibly due to the construction of the Three Gorges Dam [6], while water turbidity increased rapidly due to sand dredging activities [6,7]. In addition, laboratory analysis of water samples has shown signs of eutrophication in Poyang Lake during 2009 and 2011, where large phytoplankton biomass (occasionally $>1 \mathrm{mg} \cdot \mathrm{L}^{-1}$ ) was observed in certain regions [8]. However, there has been no systematic effort to assess the spatial and temporal patterns of phytoplankton blooms in Poyang Lake, and the eutrophic conditions of the lake water are generally unknown. Furthermore, such information is essential for environmental evaluations and ecological conservation planning, thus being highly desirable.

The limited information on the eutrophic state of Poyang Lake is due to technical difficulties. Traditional field sampling methods are often insufficient to derive statistically-meaningful results due to the low spatial and temporal coverage, especially for the dynamic Poyang Lake. Although satellite remote sensing, in theory, can provide synoptic and frequent estimates of Chl-a distributions (a proxy for biomass and eutrophication), it is notoriously difficult to derive Chl-a for turbid inland lakes due to large uncertainties in atmospheric correction and bio-optical inversion. For example, although the ocean bands of MODIS and SeaWiFS have high signal-to-noise ratios (SNRs) [9], the coarse spatial resolution $(1.1 \mathrm{~km})$ makes them difficult to apply to small water bodies. While the spatial resolution of Landsat $\mathrm{TM} / \mathrm{ETM}+$ is much higher $(30 \mathrm{~m})$, the limited spectral information and low SNR, as well as the infrequent coverage (16-day revisit cycle) also limit their use in resolving Chl-a distributions in the turbid and dynamic Poyang Lake (Figure 1). 


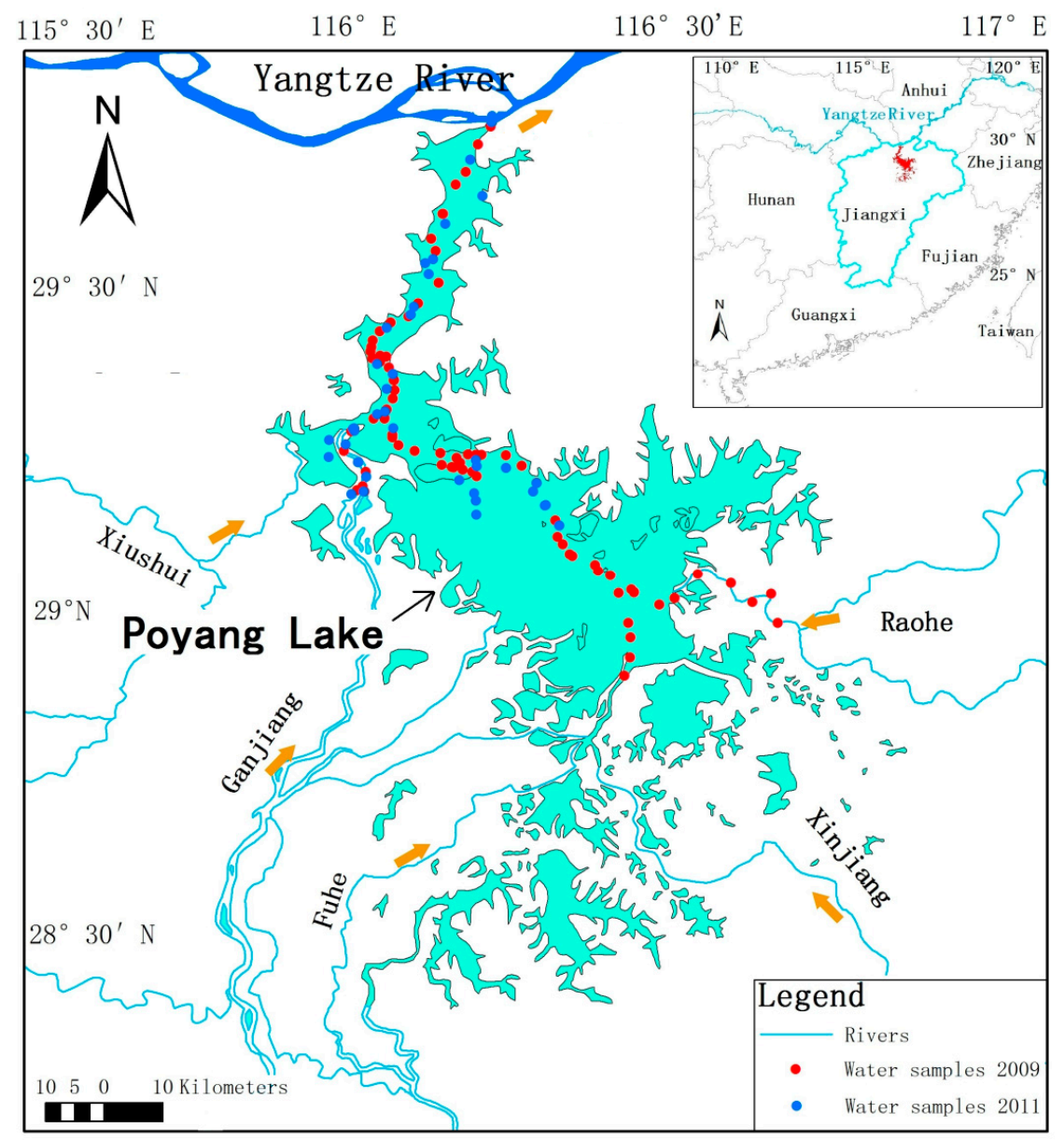

Figure 1. Location of Poyang Lake, the largest freshwater lake in China. The inset figure shows the lake's drainage basin. Red and blue points represent the in situ stations during the two cruise surveys in 2009 and 2011, respectively, and orange arrows show the water flow directions.

The difficult situation that Poyang Lake is facing when satellite remote sensing is to be used to estimate Chl-a distributions is not unique. Rather, most inland lakes have similar problems of eutrophication, a lack of systematic information and the same difficulties in remote sensing techniques. Thus, developing a practical approach to overcome the technical difficulties in remote sensing of Poyang Lake Chl-a distributions is an urgent task for the remote sensing community for its general relevance in inland water-quality assessment.

The recent availability of full-resolution (300-m) data collected by the Medium Resolution Imaging Spectrometer (MERIS) provides some potential in estimating Chl-a distributions in Poyang Lake, as MERIS has more spectral bands (15 bands) than other ocean color instruments with sufficient SNRs over the full dynamic range. Indeed, MERIS has been widely used in inland and coastal water quality assessment [10-12]. However, due to data policies, MERIS full-resolution data over global inland waters did not become available until 2013, when the U.S. NASA and the European Space Agency (ESA) reached an agreement.

Thus, given the availability of MERIS full-resolution (FR) data and motivated by the urgent information need on the eutrophic status of Poyang Lake, long-term MERIS data between 2003 and 2012 together with in situ measurements from two field surveys in 2009 and 2011 were used in this study to reach the following objectives: 
(1) To develop a practical remote sensing algorithm to retrieve Chl-a concentration of Poyang Lake whenever interference from total suspended sediments (TSS) does not present a significant problem;

(2) To document the spatial-temporal patterns of Chl-a in Poyang Lake, thus filling the knowledge gap for the potential eutrophic regions in Poyang Lake;

(3) To establish a Chl-a environmental data record (EDR) for Poyang Lake, which serves as a critical information base for future environmental conservation planning.

The manuscript is arranged as follows: The environmental settings of Poyang Lake are described first, followed by the development of the practical Chl-a algorithm. Then, we present the seasonal and inter-annual changes of the Chl-a distribution patterns in Poyang Lake, with their potential driving forces discussed. Finally, the algorithm's validity and the implications of this work are discussed.

\section{Study Area and Environmental Settings}

Poyang Lake is located in the north of Jiangxi Province $\left(28^{\circ} 22^{\prime}-29^{\circ} 45^{\prime} \mathrm{N}\right.$ and $115^{\circ} 47^{\prime}-116^{\circ} 45^{\prime} \mathrm{E}$, Figure 1), which has an average water depth of $\sim 8.4 \mathrm{~m}$ and a storage capacity of 27.6 billion $\mathrm{m}^{3}$ when the water level at Hukou is $21.71 \mathrm{~m}$ [13]. The lake is about 173-km long from the south to the north, and its maximum width (west to east) is $74 \mathrm{~km}$. The local weather is influenced by the subtropical monsoons with significant seasonality in precipitation [14]. The inundation area shows significant intra-annual variation, from $>3000 \mathrm{~km}^{2}$ in the wet seasons (April to September) to $<1000 \mathrm{~km}^{2}$ in the dry seasons (October to March) [15]. Runoff of five tributaries (Ganjiang, Fuhe, Xiushui, Xinjiang and Raohe) and local precipitation are the main water supply of Poyang Lake. Typically, the lake current direction is south to north, with water discharged to the Yangtze River in the north. Occasionally, a river-lake reversal flow also occurs when the water levels of the Yangtze River increase during the summer [16].

The turbidity of Poyang Lake has rapidly increased due to sand dredging activities [6], leading to serious environmental problems, such as fish population decline and wetland shrinkage [17,18]. In addition, the water of Poyang Lake has indicated eutrophication in recent years [8]. Evidence from previous studies indicated that nutrient concentration (nitrogen and phosphorus) has exceeded the eutrophication level [4,19], leading to algae blooms in certain lake regions. For example, a $10 \mathrm{~km}-$ long cyanobacteria bloom was observed by a routine field survey of the local wetland protection agency in 2012 [20]. However, to date, there has been no report or systematic assessment on the eutrophication status of Poyang Lake, and when and where algal blooms are likely to occur are generally unknown.

\section{Data and Methods}

\subsection{Remote Sensing Data}

Level-1 MERIS data (reprocessing version of R2012.1) covering the study region were obtained from NASA's Goddard Space Flight Center (GSFC). Of the $>700$ FR data "granules" (i.e., individual scenes) during the entire satellite mission from January 2003, to April 2012, 325 scenes were selected after visual examination to exclude those with significant clouds, sun glint and thick aerosols.

The Level-1 data were processed using the SeaDAS software (version 6.4) provided by NASA. After correction of Rayleigh scattering and gaseous absorption effects, the Rayleigh-corrected reflectance $\left(R_{\mathrm{rc}}\right)$ data were geo-referenced into a cylindrical equidistance (rectangular) projection. $R_{\mathrm{rc}, \lambda}$ was derived as: 


$$
R_{\mathrm{rc}, \lambda}=\pi L_{\mathrm{t}, \lambda}{ }^{\prime} /\left(F_{0, \lambda} \times \cos \theta_{0}\right)-R_{\mathrm{r}, \lambda}
$$

where $\lambda$ is the wavelength of the MERIS spectral band, $L_{\mathrm{t}}{ }^{\prime}$ is the calibrated at-sensor radiance after correction for gaseous absorption, $F_{0}$ is the extraterrestrial solar irradiance and $\theta_{0}$ is the solar zenith angle. $R_{\mathrm{r}}$ is the reflectance due to Rayleigh (molecular) scattering, which could be accurately estimated using analytical formulations [21]. The reason for using $R_{\mathrm{rc}}$ instead of the fully-atmospherically corrected remote sensing reflectance $\left(R_{\mathrm{rs}}, \mathrm{sr}^{-1}\right)$ is because, currently, there is no valid atmospheric correction approach for Poyang Lake: the use of SeaDAS-embedded standard atmospheric correction [21-23] and the associated quality control protocols [24] often led to false masking, resulting in significant data loss in the retrieved $R_{\mathrm{rs}}$; the use of the BEAM software from the European Space Agency (the "Lake Module" and "Neural Network Module" for atmospheric correction) did not work either, and even the derived $R_{\mathrm{rs}}$ spectral shape was not correct, not to mention the magnitude [25].

\subsection{In Situ Measurements}

Two field surveys were conducted in October, 2009 (17-26 October), and July, 2011 (15-23 July), representing the dry and wet conditions of Poyang Lake, respectively. The 98 in situ stations are annotated in Figure 1. During these surveys, water samples were collected to determine Chl-a and TSS concentrations. When weather conditions permitted, surface reflectance was also measured. The procedures and methods for these field measurements and data reduction are described briefly as follows:

(1) ASD FieldSpec Pro FR2500 spectroradiometer (Analytical Spectral Devices, Inc., USA, 350 to $2500 \mathrm{~nm}$ with 4-nm increments) was used to measure the above-water hyperspectral remote sensing reflectance $\left(R_{\mathrm{rs}}, \mathrm{sr}^{-1}\right)$ following the NASA-recommended protocols [26]. All measurements were conducted from 10 am to 2 pm local time under clear sky conditions without apparent whitecaps or foam on the water surface. For each $R_{\mathrm{rs}}$ measurement, upward radiance $\left(\mathrm{L}_{\mathrm{u}}\right)$, downward sky radiance ( $\left.\mathrm{L}_{\text {sky }}\right)$ and radiance from a standard Specrtralon reference plaque ( $\left.\mathrm{L}_{\text {plaque }}\right)$ were measured. $\mathrm{R}_{\mathrm{rs}}$ was then derived as [26],

$$
\mathrm{R}_{\mathrm{rs}}=\rho_{\text {plaque }}\left(\mathrm{L}_{\mathrm{u}}-\rho_{\mathrm{f}} \times \mathrm{L}_{\text {sky }}\right) /\left(\pi \mathrm{L}_{\text {plaque }}\right)
$$

where $\rho_{\text {plaque }}$ is the reflectance of the reference plaque ( $\sim 30 \%$, provided by the manufacture $)$ and $\rho_{\mathrm{f}}$ is the Fresnel reflectance of the water surface (assumed to be 0.022 for a calm water surface) [26]. Several examples of $R_{\mathrm{rs}}$ and their corresponding Chl-a and TSS values are presented in Figure 2a.

(2) Chl-a concentration (in $\mathrm{mg} \cdot \mathrm{m}^{-3}$ ) was measured using an RF-5301 Fluorescent Spectrophotometer (Shimadzu, Kyoto, Japan), calibrated by the Chl-a standards manufactured by Sigma Chemical Co. (St. Louis, MO, USA). In short, water samples were filtered through 0.45-um Whatman cellulose acetate membranes and then immediately stored in liquid nitrogen. The filters were then soaked with acetone (90\%) to extract the Chl-a pigment, and a centrifuge was used to increase the extraction efficiency. After storing at $0{ }^{\circ} \mathrm{C}$ for $24 \mathrm{~h}$, Chl-a was determined by measuring the extracted pigment samples. The mean Chl-a concentration for all of the water samples was determined to be $4.9 \pm 3.3 \mathrm{mg} \cdot \mathrm{m}^{-\mathrm{g}}$.

(3) To measure TSS concentration (in $\mathrm{mg} \cdot \mathrm{L}^{-1}$ ), the water sample was filtered on a weighted Whatman cellulose acetate membrane filter. After drying in a $45{ }^{\circ} \mathrm{C}$ oven for $24 \mathrm{~h}$, the filter was weighed again, and TSS was determined by the weight difference divided by the filtered water volume. 
An analytical balance with a precision of $0.01 \mathrm{mg}$ was used to weigh the filters. Mean TSS for all samples was $88.6 \pm 92.0 \mathrm{mg} \cdot \mathrm{L}^{-1}$.

(4) To measure the absorption of colored dissolved organic materials (CDOM), water samples were filtered through $0.2-\mu \mathrm{m}$ Millipore membrane filters. Then, their absorbance was measured with an Ocean Optics HR2000 spectrometer, a PX-2 light source and a liquid waveguide capillary cell with 1-m optical path length. The absorbance data were then converted to the absorption coefficient as $a_{\mathrm{CDOM}}(\lambda)=A_{\mathrm{CDOM}}(\lambda) \times \ln (10) / 1.0(\mathrm{~m})$. The mean $a_{\mathrm{CDOM}}(\lambda)$ of all samples at $560 \mathrm{~nm}$ was determined to be $0.13 \pm 0.07 \mathrm{~m}^{-1}[27]$.

\subsection{Other Auxiliary Data}

Monthly precipitation over the Poyang Lake drainage basin was estimated from monthly Tropical Rainfall Measuring Mission satellite measurement (TRMM 3B43) products, which were downloaded from NASA's Goddard Distributed Active Archive Center (DAAC). These data were validated using discrete rain gauges in the drainage basin [15]. Surface runoff data were collected at hydrologic stations at five tributaries. Long-term TSS distribution maps derived from MODIS data between 2000 and 2010 using a regional algorithm were also obtained [28], and the data were resampled to the same spatial resolution of MERIS. These data were used to understand the short-term to long-term changes of Chl-a in Poyang Lake.

\section{Algorithm Development}

\subsection{NGRDI-Based Algorithm}

Since the Coastal Zone Color Scanner (CZCS) began to collect data in 1978, blue-green band ratios have been used to estimate Chl-a concentration in surface Case I waters [29], where the reflectance is primarily influenced by the absorption and scattering of phytoplankton particles [30]. For turbid Case II waters, the surface reflectance of these spectral bands is strongly affected by CDOM and/or suspended particles [30]. Therefore, the candidate wavelengths have been moved to red and near-infrared (NIR) spectral regions, where the influence of CDOM and/or particles is relatively small [11,12,31]. However, to date, there has been no universal Chl-a retrieval algorithm for inland and coastal waters, due to the changing constituent compositions (i.e., different compositions of CDOM, Chl-a and suspended particles), phytoplankton structure and other optical complexity among different water bodies [32,33]. As for Poyang Lake, although several TSS models have been proposed [28], no attempt has been reported to derive Chl-a concentration using remotely-sensed data. Previous proposed two-band [34] and three-band [35] algorithms for in situ $\mathrm{R}_{\mathrm{rs}}$ showed poor performance in retrieving Chl-a (see below). Thus, developing a valid Chl-a retrieval algorithm becomes the first task of the current study.

To select the candidate wavelengths for Chl-a retrieval algorithms for Poyang Lake, concurrent in situ $R_{r s}$ spectra, Chl-a and TSS data were visualized (see Figure 2a). The magnitude of $R_{r s}$ appears highly correlated with TSS, as $R_{r s}$ increases monotonically with increasing TSS. Meanwhile, no such monotonic spectral change was found for various Chl-a concentrations. To reduce the effect of water turbidity to the first order, the raw $R_{r s}$ data were then normalized as [35]: 


$$
\mathrm{R}_{\mathrm{rs}}{ }^{\prime}\left(\lambda_{\mathrm{i}}\right)=\mathrm{R}_{\mathrm{rs}}\left(\lambda_{\mathrm{i}}\right) / \int_{400}^{1000} \mathrm{R}_{\mathrm{rs}}\left(\lambda_{\mathrm{i}}\right) \mathrm{d} \lambda
$$

Figure $2 \mathrm{~b}$ shows that the amplitude of normalized $R_{r s}$ spectrum decreased with increasing TSS, and the spectral shape was similar when TSS concentration was at the same level. Yet, for TSS $<100 \mathrm{mg} \mathrm{L}^{-1}$, the pectral variability of different Chl-a could be identified between 500 and $700 \mathrm{~nm}$, suggesting a potential relationship between Chl-a and $R_{r s}(500-700 \mathrm{~nm})$. Particularly, an absorption feature between 660 and $690 \mathrm{~nm}$ is prominent in the two blue curves. Unfortunately, when TSS reached $>100 \mathrm{mg} \cdot \mathrm{L}^{-1}$ (dashed and solid yellow curves), the spectral shape was nearly identical, even when Chl-a changed by greater than two-fold. This result suggests that the signal of Chl-a in high-TSS waters, if any, is overwhelmed by TSS, and it is nearly impossible to estimate Chl-a accurately in these waters.
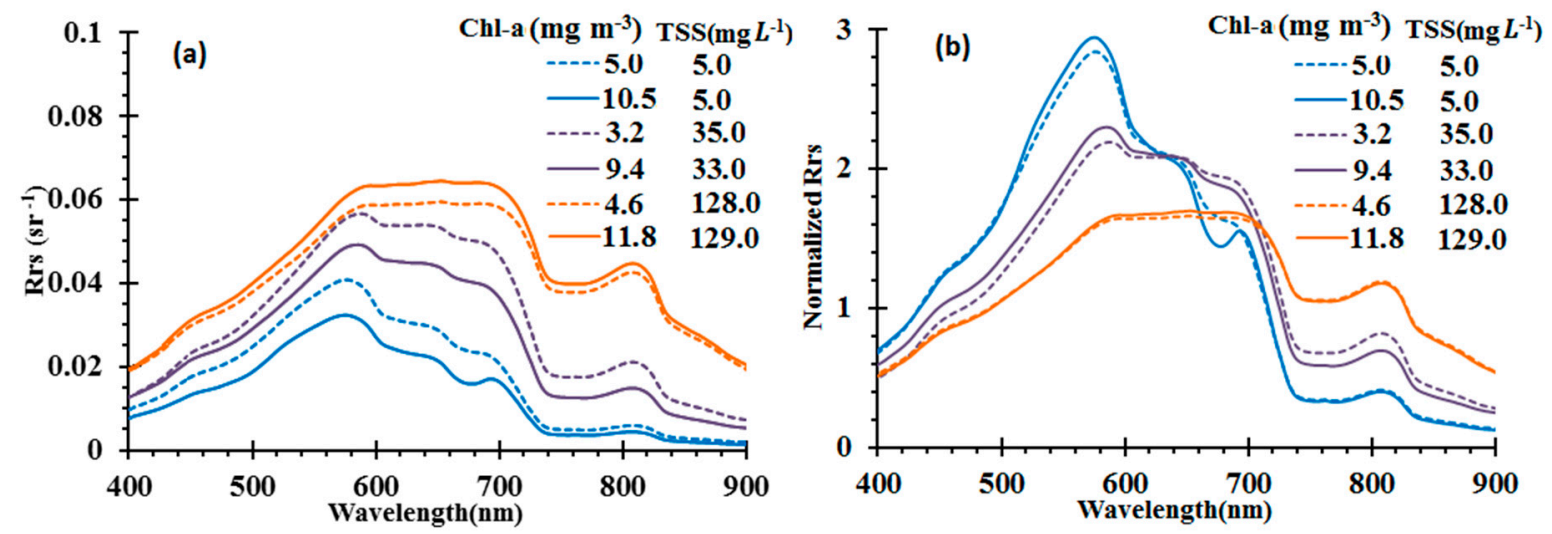

Figure 2. Typical raw (a) and normalized (b) $R_{r s}$ at different Chl-a and total suspended sediment (TSS) concentrations. While the raw $R_{r s}$ increase monotonously with TSS, the spectral difference between 500 and $700 \mathrm{~nm}$ could be observed in the normalized $R_{r s}$ when TSS is not extremely high.

To further reveal the specific spectral features between 500 and $700 \mathrm{~nm}$ and to remove the first-order signal of TSS, normalized Rrs spectra for different Chl-a concentrations were compared. As shown in Figure 3a, when Chl-a increased from 1.3 to $10.5 \mathrm{mg} \cdot \mathrm{m}^{-3}$, normalized $\mathrm{R}_{\mathrm{rs}}$ increased monotonously between 550 and $600 \mathrm{~nm}$ and decreased between 650 and $700 \mathrm{~nm}$. Thus, the normalized $\mathrm{R}_{\mathrm{rs}}$ difference between the two spectral regions should be sensitive to changes in Chl-a (Figure 3b). Indeed, MERIS Band 5 (560 nm), Band $7(665 \mathrm{~nm})$ and Band $8(681 \mathrm{~nm})$ are located in these two spectral regions. Absorption coefficients of phytoplankton pigments determined from water samples showed minima and maxima at 560 and $675 \mathrm{~nm}$, respectively, corresponding to the MERIS bands at $560 \mathrm{~nm}$ and $681 \mathrm{~nm}$ (gray shaded lines in Figure 3a,b). Therefore, a normalized green-red difference index (NGRDI) based on MERIS 560-nm and 681-nm bands was used to relate to surface Chl-a concentrations of Poyang Lake, which is defined as:

$$
\mathrm{NGRDI}=\left(\mathrm{R}_{\mathrm{rs}, 560}-\mathrm{R}_{\mathrm{rs}, 681}\right) /\left(\mathrm{R}_{\mathrm{rs}, 560}+\mathrm{R}_{\mathrm{rs}, 681}\right)
$$



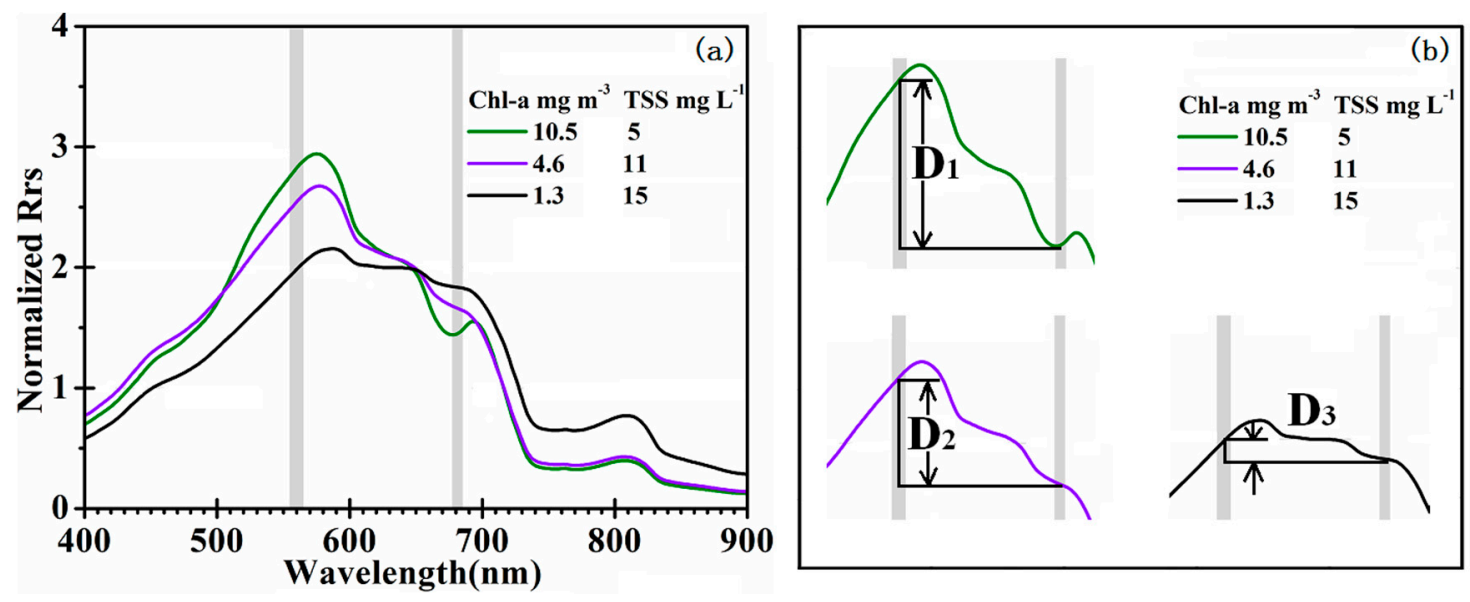

Figure 3. (a) Comparison of the normalized $R_{r s}$ with different Chl-a concentrations. The relative difference between MERIS 560- and 681-nm bands $\left(D_{i}\right.$ of $\left.(\mathbf{b})\right)$ increases with elevated Chl-a.

NGRDI, based on in situ $\mathrm{R}_{\mathrm{rs}}$ at MERIS wavelengths of 560 and $681 \mathrm{~nm}$, together with concurrent Chl-a measurements, was used to establish a Chl-a retrieval algorithm. In the initial attempt, the 665-nm band was also used to replace the 681-nm band, yet the performance was less satisfactory. Figure 4 shows that although Chl-a is not correlated with NGRDI in TSS-rich turbid waters for the reasons outlined above (also see Figure 2b), for low-TSS waters (bluish points), Chl-a increased with increasing NGRDI, suggesting that for low-TSS waters, Chl-a could be derived from NGRDI. To determine the cut-off NGRDI threshold for the algorithm applicability, empirical exponential algorithms were established for different NGRDI levels (0-0.2), with algorithm coefficients and performance listed in Table 1 . The reason for using an exponential from is that its regression performance (as gauged by $R^{2}$, mean relative error (MRE) and root mean square error (RMSE)) was much better than linear, polynomial, power or any other regression forms. When the NGRDI threshold changed from 0.06 to 0.2 , the correlation between NGRDI and Chl-a remained stable, with coefficients of determination $\left(R^{2}\right)$ of $0.7 \sim 0.8$ and model uncertainties (e.g., MRE and RMSE) of $<20 \%-40 \%$. When the NGRDI threshold decreased to $<0.06$, the model performance declined significantly, as indicated by lower $R^{2}$ and higher MRE and RMSE. As a compromise between algorithm accuracy and data coverage range, 0.06 was then selected as the lower limit of NGRDI for Chl-a retrievals in this study (shaded line in Table 1), and the empirical algorithm is expressed as:

$$
\text { Chl-a }\left(\mathrm{mg} \cdot \mathrm{m}^{-3}\right)=0.8724 \exp (7.0508 \times \mathrm{NGRDI})[\mathrm{NGRDI}>0.06]
$$

For the applicable NGRDI range, Chl-a ranged between 1.3 and $10.5 \mathrm{mg} \cdot \mathrm{m}^{-3}$ with model uncertainties of $30 \%-40 \%$ in terms of MRE and RMSE (Figure $5 \mathrm{a}$ ). In addition, the leave-one-out cross-validation (LOOCV) analysis [36] showed acceptable overall uncertainties in the estimated Chl-a. The LOOCV analysis used all but one data point to establish an empirical model to predict Chl-a for the excluded data point. The procedure was repeated for every data point, with statistics presented in Figure 5b, where both MRE and RMSE were shown to be $<40 \%$. Such model uncertainties are similar to the $35 \%$ goal of typical ocean color missions in estimating Chl-a concentrations [37] and lower than the 50\%-60\% uncertainties of satellite-derived chlorophyll-a concentrations over the global open ocean [38]. Note that although the effect 
of the measured CDOM absorption cannot be neglected at $560 \mathrm{~nm}$ (mean absorption $=0.13 \pm 0.07 \mathrm{~m}^{-1}$ ), such an effect is implicitly included in the empirical regression in Equation (5).

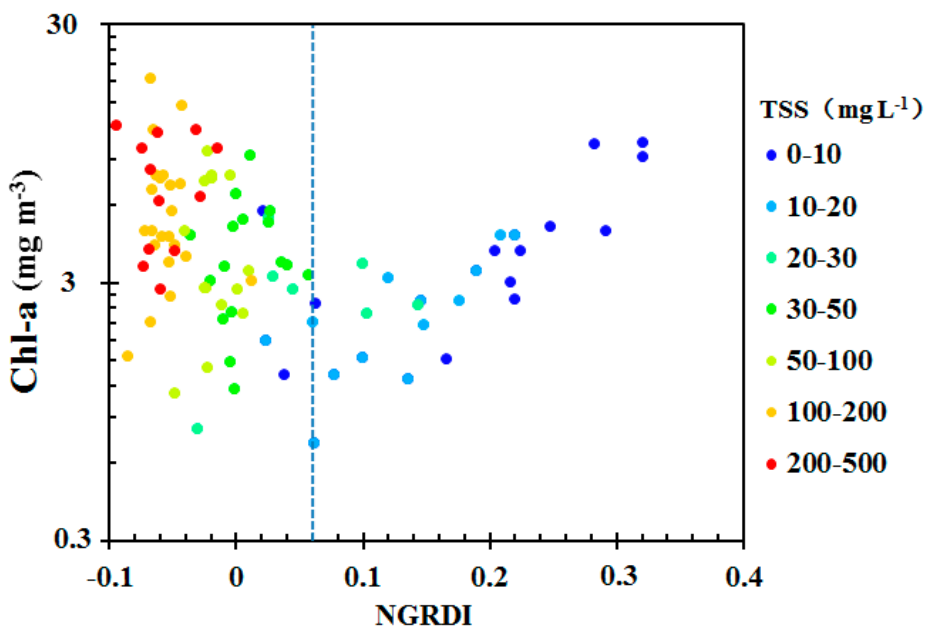

Figure 4. Relationship between normalized green-red difference index (NGRDI = $\left(\mathrm{R}_{\mathrm{rs}, 560}-\mathrm{R}_{\mathrm{rs}, 681}\right) /\left(\mathrm{R}_{\mathrm{rs}, 560}+\mathrm{R}_{\mathrm{rs}, 681)}\right)$ and Chl-a concentration. Although no correlation was found for sediment-rich (TSS $>25 \mathrm{mg} \cdot \mathrm{L}^{-1}$ ) waters, a positive correlation exists between Chl-a and NGRDI in relatively sediment-poor waters. The dashed blue line indicates the lower limit of the NGRDI, where the NGRDI-based Chl-a algorithm can be used.

Table 1. Chl-a algorithms at different NGRDI levels (0-0.2) based on in situ $R_{r s}$ and Chl-a measurements. Their associated performances are also listed. The bolded line represents a compromise between algorithm accuracy and data coverage and is therefore selected as the model in this study (NGRDI > 0.06) to apply to the entire MERIS dataset.

\begin{tabular}{cccccc}
\hline NGRDI & Samples & Model & $\boldsymbol{R}^{\mathbf{2}}$ & MRE (\%) & RMSE (\%) \\
\hline$>0.2$ & 11 & $\mathrm{y}=0.5892 \mathrm{e}^{8.6879 x}$ & 0.68 & 20.9 & 27.6 \\
$>0.18$ & 12 & $\mathrm{y}=0.6309 \mathrm{e}^{8.4433 \mathrm{x}}$ & 0.70 & 19.9 & 26.8 \\
$>0.16$ & 14 & $\mathrm{y}=0.4623 \mathrm{e}^{9.5981 \mathrm{x}}$ & 0.76 & 21.5 & 27.7 \\
$>0.14$ & 17 & $\mathrm{y}=0.6048 \mathrm{e}^{8.5652 \mathrm{x}}$ & 0.79 & 20.3 & 27.6 \\
$>0.12$ & 18 & $\mathrm{y}=0.5284 \mathrm{e}^{9.094 \mathrm{x}}$ & 0.81 & 21.5 & 28.0 \\
$>0.10$ & 20 & $\mathrm{y}=0.756 \mathrm{e}^{7.639 \mathrm{x}}$ & 0.73 & 24.8 & 32.3 \\
$>0.07$ & 23 & $\mathrm{y}=0.874 \mathrm{e}^{7.0421 \mathrm{x}}$ & 0.71 & 25.4 & 33.8 \\
$>\mathbf{0 . 0 6}$ & $\mathbf{2 5}$ & $\mathbf{y}=\mathbf{0 . 8 7 2 4} \mathrm{e}^{7.0508 x}$ & $\mathbf{0 . 7 0}$ & $\mathbf{2 8 . 6}$ & $\mathbf{3 7 . 8}$ \\
$>0.05$ & 27 & $\mathrm{y}=1.076 \mathrm{e}^{6.1187 \mathrm{x}}$ & 0.62 & 32.2 & 43.0 \\
$>0.04$ & 28 & $\mathrm{y}=1.1925 \mathrm{e}^{5.649 \mathrm{x}}$ & 0.57 & 34.1 & 45.9 \\
$>0.03$ & 31 & $\mathrm{y}=1.3058 \mathrm{e}^{5.2318 \mathrm{x}}$ & 0.53 & 36.1 & 48.4 \\
$>0.02$ & 37 & $\mathrm{y}=2.1724 \mathrm{e}^{2.8184 \mathrm{x}}$ & 0.20 & 46.0 & 66.9 \\
$>0$ & 41 & $\mathrm{y}=2.4048 \mathrm{e}^{2.3081 \mathrm{x}}$ & 0.15 & 46.1 & 69.0 \\
\hline
\end{tabular}

As a comparison, Figure 5c,d also shows the performances of the three-band [35] and two-band [34] algorithms, respectively, using the same Poyang Lake in situ data. Additionally, other Chl-a algorithms developed for coastal or inland waters of China or elsewhere, such as the NDCI (normalized difference chlorophyll-a index) approach [39] and four-band model [40,41], which all involved an NIR band, also 
showed poor performances in Poyang Lake (results not shown here). This may be due to the reason that the signal of the NIR band in these methods is disturbed even with moderate sediment concentration. The Red-Green Chl-a Index (RGCI) was proposed by Le et al. [42] to document the Chl-a changes in Tampa Bay; however, the red-green band ratios showed insignificant relationships with the Chl-a concentration of Poyang Lake. Thus, these well-established algorithms are not applicable for Poyang Lake. In fact, various green-red combinations have been used for vegetation monitoring [43], while in this study, we introduced a normalized index with the form of (Red-Green)/(Red + Green) to obtain the Chl-a concentration in a relatively turbid inland lake.
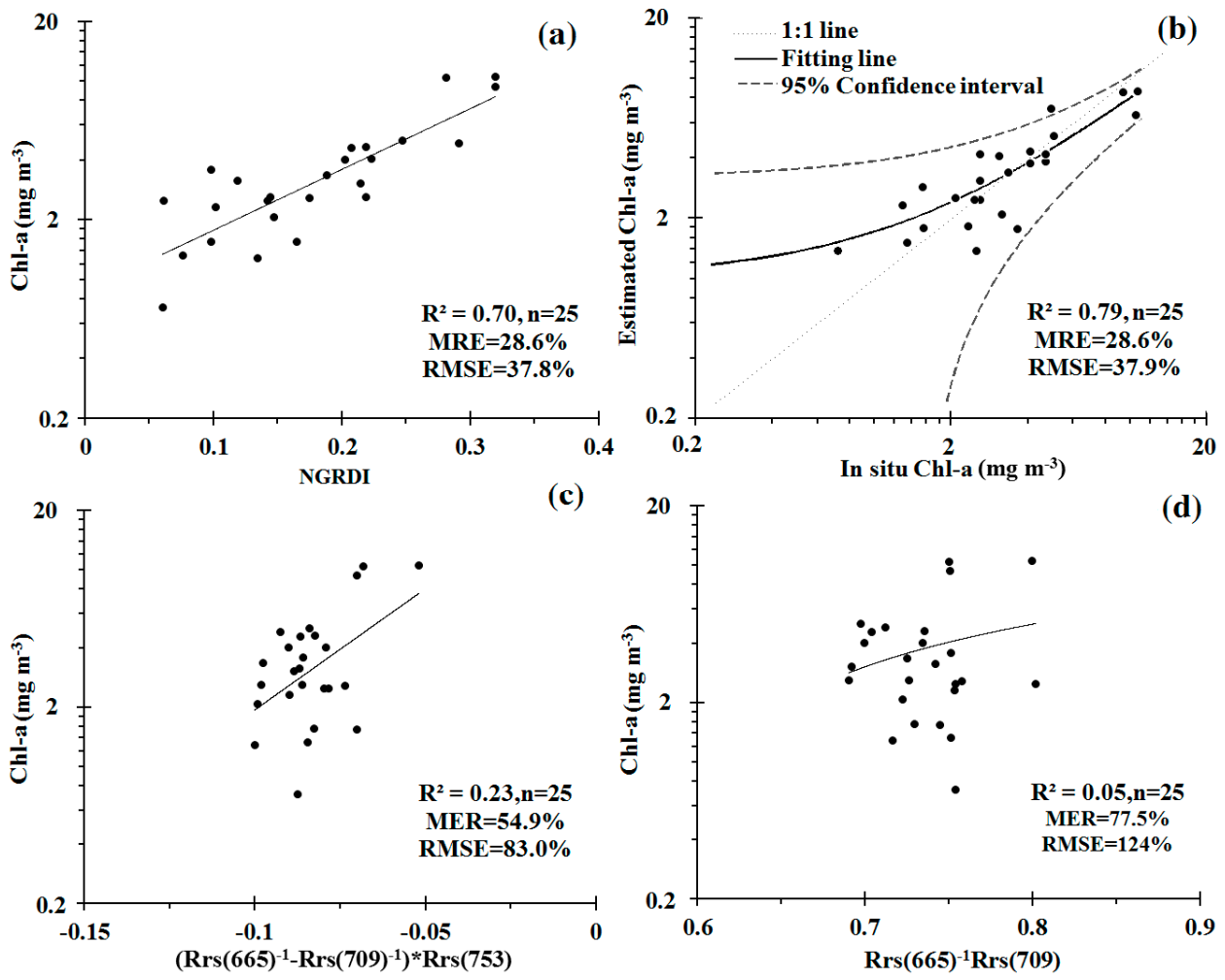

Figure 5. (a) The selected empirical NGRDI-Chl-a model and its performance; (b) the model performance from the leave-one-out cross-validation (LOOCV) analysis. For comparison, the performances of the three-band and two-band models are shown in (c) and (d), respectively.

\subsection{Application to MERIS Data}

The established Chl-a retrieval algorithm is based on field-measured $R_{\mathrm{rs}}$ data. Ideally, MERIS data should be atmospherically corrected [44] to derive validated $R_{\mathrm{rs}}$ and then used in the algorithm. In practice, this is currently impossible for a number of reasons, including high turbidity, land adjacency effect and complex aerosol properties. Indeed, before the practical atmospheric correction was developed and used for this study, several popular algorithms and software packages were attempted in order to derive reasonable $R_{\text {rs }}$ data from the MERIS measurements (see supplemental materials, Figures S1-S3). These included both NASA's software SeaDAS and ESA's software BEAM. The algorithm embedded in SeaDAS (version 6.4) (both near-infrared-based and shortwave infrared-based) $[21,22,45]$ is based on pre-computed lookup tables (LUTs), established using radiative transfer theory, which has been widely used within the ocean color community. Yet, the algorithm often masked many water pixels, and for non-masked water 
pixels, the algorithm always resulted in negative $R_{\mathrm{rs}}$ values. Likewise, atmospheric correction in the "Lake Module" and "Neural Network Module" of the BEAM software did not work either, and even the derived $R_{\text {rs }}$ spectral shape was not correct, not to mention the magnitude (results not shown here) $[25,46]$. The exact reason was unknown, but could possibly be due to the fact that these BEAM plug-in modules were primarily developed for European waters, where optical constraints used in the iterative atmospheric correction could be drastically different from those for Chinese lakes. Thus, before a validated atmospheric correction approach is developed, alternative ways must be sought to derive the surface reflectance from MERIS measurements.

In this study, MERIS data partially corrected for the atmospheric effects, namely the Rayleigh-corrected reflectances $\left(R_{r c}\right.$, Equation (1)) were used as surrogates of $R_{r s}$ to feed the Chl-a retrieval algorithm of Equation (5). The errors induced by this approach were assessed and then removed through simulations of the algorithm sensitivity to variable aerosols and observing geometries in the following way.

According to radiative transfer theory [21], the Rayleigh-corrected reflectance $R_{r c}$ can be expressed as:

$$
R_{r c}=\rho_{a}+t_{0} \times t \times \pi \times R_{r s}
$$

where $\rho_{a}$ represents reflectance due to aerosol scattering and aerosol-Rayleigh interactions, $t_{0}$ is the total (Rayleigh + aerosol) diffuse transmittance from the Sun to the target and $t$ is the total diffuse transmittance from the target to the sensor. Note that for simplicity, their dependence on wavelength is omitted in Equation (6). For a given $R_{r s}$ spectrum, $R_{r c}$ at MERIS 560-nm and 681-nm bands can be calculated using Equation (6) under various observing scenarios (solar/viewing geometry and variable aerosol contents). Then, both $R_{r s}$ and $R_{r c}$ were used to derive Chl-a and Chl-a', respectively, using the same Equation (5). The difference between Chl-a' and Chl-a is derived and regarded as the error from the partial atmospheric orrection.

In the sensitivity analysis, two solar/viewing scenarios with satellite zenith of $\theta=4^{\circ}$ and $57^{\circ}$, respectively were simulated, representing the MERIS scene center and scene edge, respectively. $\rho_{\mathrm{a}}$ for various aerosol types (maritime, coastal and troposphere aerosols) and optical thickness $\left(\tau_{\mathrm{a}}(865)\right.$ from 0.03 to 0.4$)$ were estimated with aerosol lookup tables embedded in SeaDAS [47] for the two scenarios. The two $\tau_{\mathrm{a}}(865)$ extremes represent clear and turbid atmosphere, respectively (note that $\tau_{\mathrm{a}}(865)=0.3$ is the high aerosol flagging threshold used in SeaDAS processing) [48].

Relative differences of ([Chl-a] - [Chl-a'])/[Chl-a]) for two typical aerosol models and two solar/viewing scenarios are plotted in Figure 6. Here, Chl-a represents those derived from the NGRDI algorithm with $R_{r s}$ as algorithm inputs, while Chl-a' represents those derived from the NGRDI algorithm with $R_{r c}$ as algorithm inputs. These results show that although the relative difference increases with increasing aerosol optical thickness, the range is small (20\% to $30 \%)$ for various solar/viewing geometry, aerosol thickness, aerosol types, as well as Chl-a concentration $\left(2-10 \mathrm{mg} \cdot \mathrm{m}^{-3}\right)$. These results suggest that $R_{r c}$-estimated Chl-a values are $20 \%-30 \%$ smaller than those estimated from $R_{r s}$ under all circumstances considered in the simulations. Thus, if $R_{r c}$-derived Chl-a were empirically lifted by $25 \%$, the difference between the resulting Chl-a and $R_{r s}$-estimated Chl-a should be $<5 \%$. Given the difficulty of a full atmospheric correction, this approach appears to be a simple, but practical method for using remote 
sensing imagery to obtain Chl-a distributions in Poyang Lake. Thus, in this study, the final Chl-a algorithm used for MERIS data over Poyang Lake is:

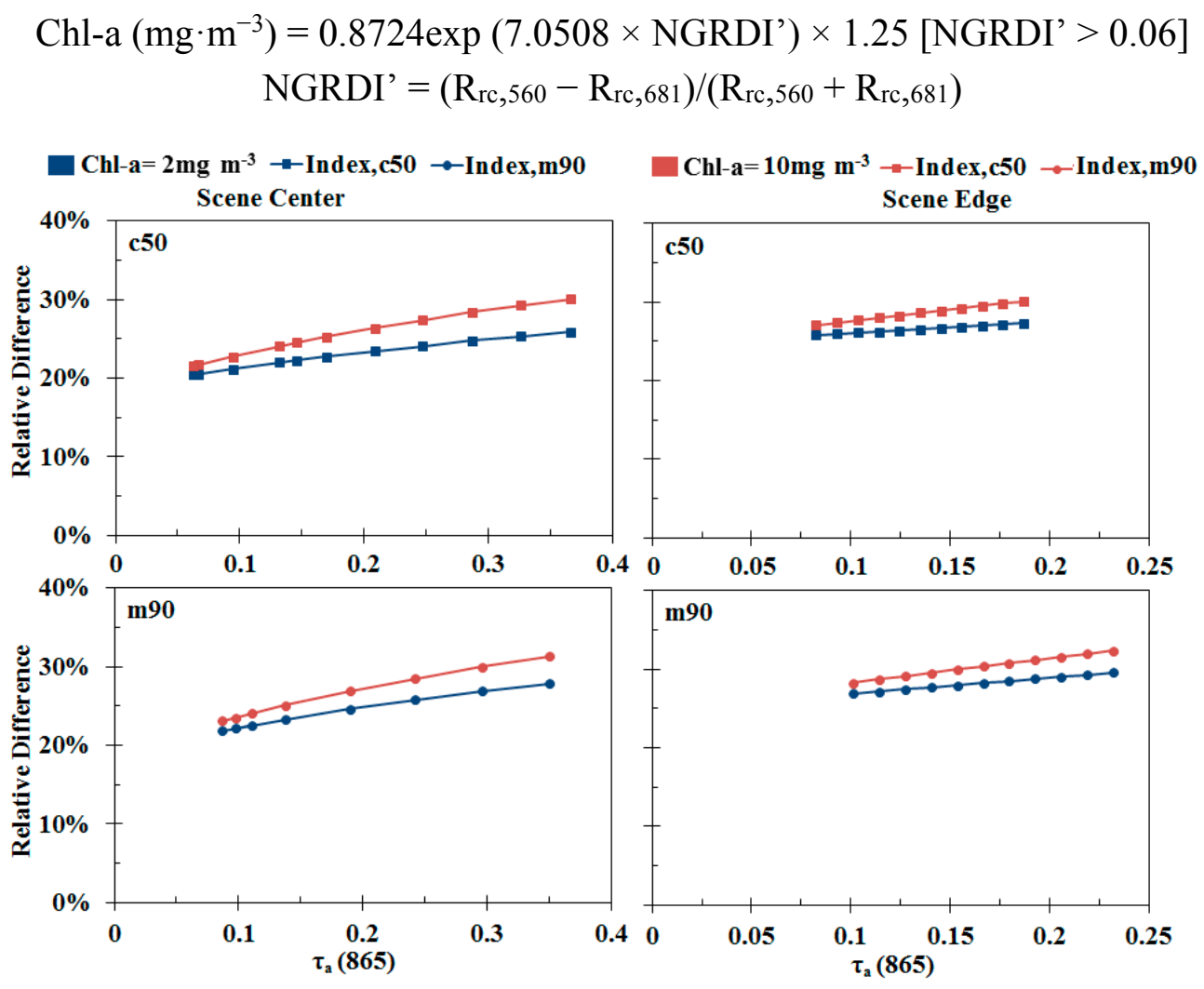

Figure 6. Relative difference between Chl-a derived from $R_{r s}$ (atmospherically-corrected remote sensing reflectance) and $R_{r c}$ (Rayleigh-corrected reflectance) using the same Equation (6). Two typical aerosol types for the open and coastal oceans are shown in this example: maritime aerosol with $90 \%$ relative humidity ( $\mathrm{m} 90)$ and coastal aerosol with $50 \%$ relative humidity $(\mathrm{c} 50) . \tau_{\mathrm{a}}(865)$ is the aerosol optical thickness at $865 \mathrm{~nm}$. (Left) The two left panels show the cases near the scene center (satellite zenith $\theta=4^{\circ}$, solar zenith $\theta_{0}=18.4^{\circ}$, relative azimuth $\phi=22^{\circ}$ ), and (Right) the two right panels are for the scene edge $\left(\theta=57^{\circ}, \theta_{0}=29^{\circ}, \phi=21^{\circ}\right)$. For Chl-a of 2 and $10 \mathrm{mg} \cdot \mathrm{m}^{-3}$, the $R_{r c}$-estimated Chl-a showed biases between 20\%-30\% regardless of the variable solar/viewing geometry, aerosol thickness or aerosol types. A first-order empirical correction of $25 \%$ can thus be applied to the $R_{r c}$-estimated Chl-a to reduce the biases.

\section{Seasonal and Inter-Annual Changes of Chl-a Concentrations}

The newly developed Chl-a algorithm was implemented to process all 325 MERIS FR scenes between 2003 and 2012 to derive the Chl-a distribution of Poyang Lake. While field measurements strictly concurrent (i.e., within \pm 3 h or at least the same day) with MERIS measurements were not available, several measures were used to evaluate the algorithm validity, including validation using near-concurrent field measurements. Such validity and applicability of the algorithm, in the context of algorithm development, in general, and applications in Poyang Lake and other similar lakes, in particular, are presented and fully discussed below (see the Discussion). 
Figure 7 shows an example of such retrieved Chl-a distributions using MERIS FR data and the algorithm in Equation (7). Compared with the corresponding RGB image in Figure 7a, most regions of the south lake show retrieved Chl-a estimates (Figure 7b). In contrast, the algorithm failed in the north lake, due to the high turbidity and, thus, lower NGRDI $(<0.06)$ in this region [6].

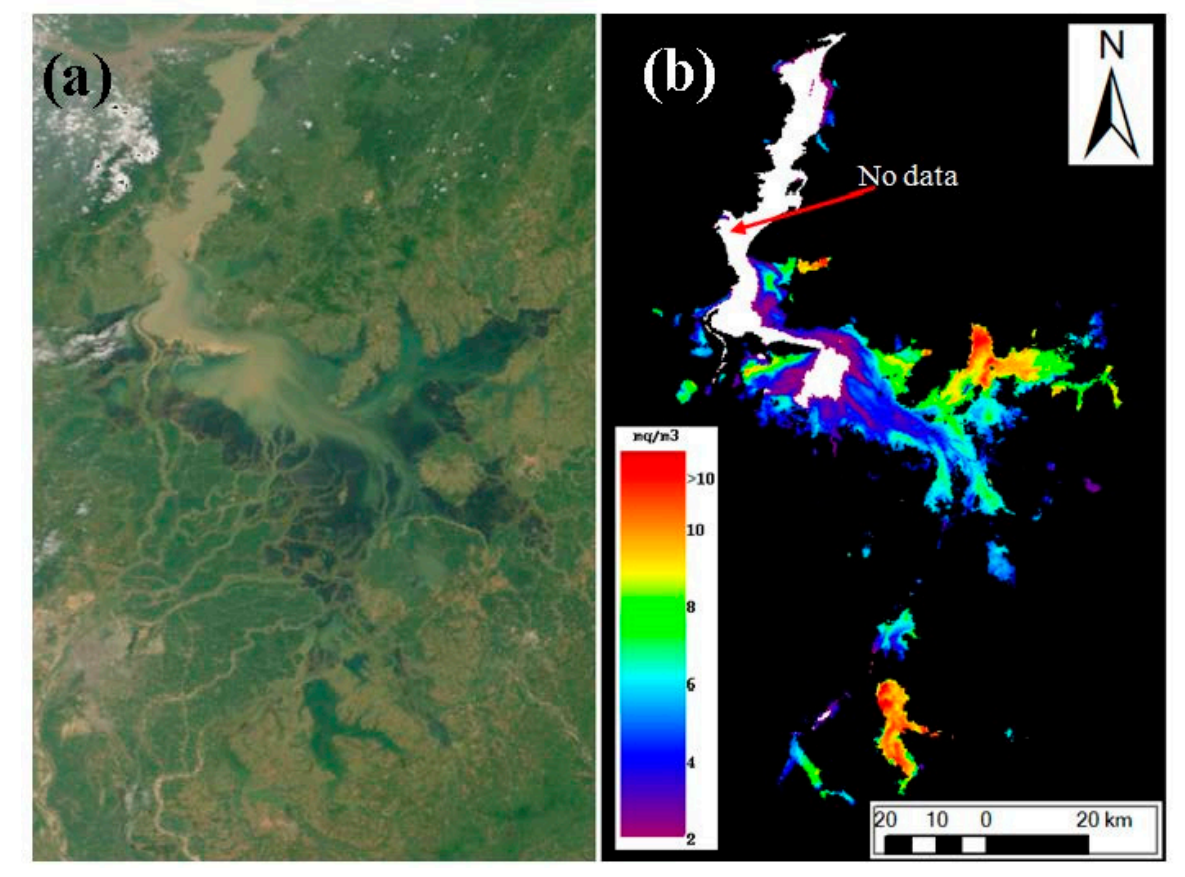

Figure 7. An example of an MERIS RGB image on August 27, 2004 (Left) and the derived Chl-a (Right) image using the NGRDI algorithm (Equation (7)). The algorithm is not applicable in the north lake (white color), where TSS dominates the spectral signal.

The 325 MERIS-derived Chl-a images between 2003 and 2012 were used to calculate monthly mean and monthly climatological Chl-a distributions in Poyang Lake. During calculating the mean, some of the masked high-TSS regions (NGRDI $<0.06$ ) in each individual image were filled by Chl-a values from other images. Figure 8 shows the monthly Chl-a climatology during the nine-year period from 2003 to 2011 (MERIS data are not available after April, 2012), where each panel is derived as the average of that month from all of the years. A significant spatial gradient was revealed during each climatological month, with clear seasonality shown across the months. While Chl-a of the north lake was lower than $2 \mathrm{mg} \cdot \mathrm{m}^{-3}$ during each month, significantly higher Chl-a was observed in the south, especially for the small sub-lake (outlined in red in the "Jul" panel). Some regions of the east lake also showed Chl-a of $>5 \mathrm{mg} \cdot \mathrm{m}^{-3}$ in July and August. In fact, Chl-a in the summer months appeared higher than in other months, as most of the south lake showed Chl-a of $>3$ or even $>5 \mathrm{mg} \cdot \mathrm{m}^{-3}$ between July and September, suggesting possible eutrophication during these months. Table 2 lists the mean Chl-a values during each climatological month in Figure 8, which were derived from the pixels where $>50 \%$ of valid Chl-a (i.e., NGRDI $>0.06$ ) retrievals were obtained from the 325 MERIS scenes. The mean Chl-a concentration ranged between $2.4 \pm 0.2 \mathrm{mg} \cdot \mathrm{m}^{-3}$ in April and $4.4 \pm 1.0 \mathrm{mg} \cdot \mathrm{m}^{-3}$ in July, with an annual mean of $3.2 \pm 0.6 \mathrm{mg} \cdot \mathrm{m}^{-3}$. 
Table 2. Chl-a mean of Poyang Lake during each climatological month derived from MERIS measurements between 2003 and 2011. Also listed in the last column is the annual mean and annual standard deviation. Note that the Std. values in the third line are the standard deviations of nine monthly mean Chl-a from 2003 to 2011.

\begin{tabular}{cccccccccccccc}
\hline & Jan & Feb & Mar & Apr & May & Jun & Jul & Aug & Sep & Oct & Nov & Dec & Annual Mean \\
\hline Mean & 2.6 & 2.9 & 2.5 & 2.4 & 3.0 & 3.4 & 4.4 & 4.2 & 3.5 & 3.3 & 3.3 & 2.9 & 3.2 \\
Std. & 0.5 & 0.6 & 0.4 & 0.2 & 0.4 & 0.8 & 1.0 & 1.0 & 0.3 & 0.3 & 0.6 & 0.6 & 0.6 \\
\hline
\end{tabular}

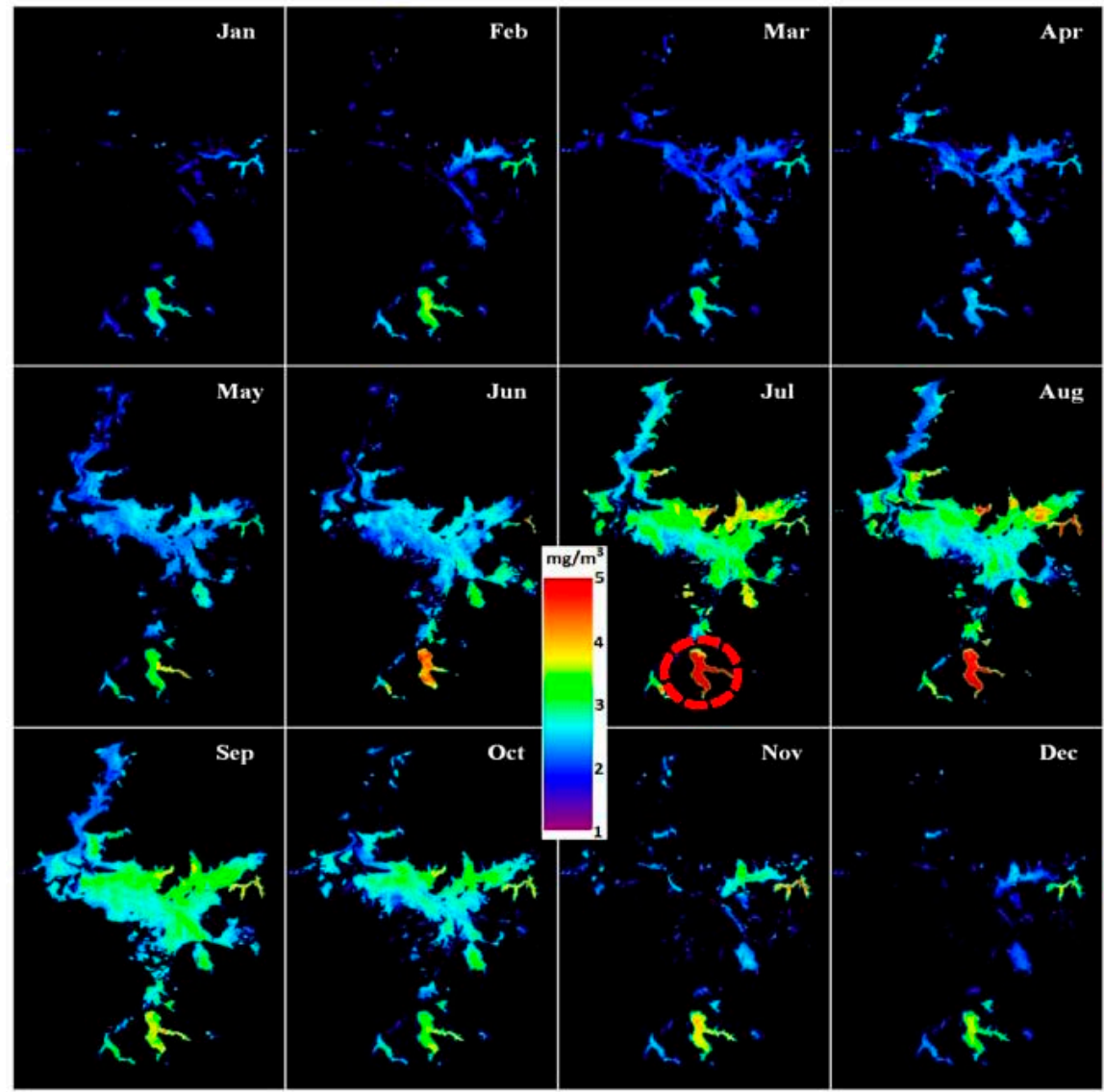

Figure 8. MERIS-derived Chl-a distributions in Poyang Lake during each climatological month between 2003 and 2012. Each panel was derived as the average of that month from all of the years. Note the significant seasonality in coverage due to lake inundation changes [15].

The arithmetic mean of the monthly Chl-a maps between July and September during each year was calculated to represent the Chl-a conditions for that year. This is because Chl-a was generally higher in these months than in other months. Figure 9 shows the Chl-a status of Poyang Lake during each year from 2003 to 2011, with the mean nine-year condition illustrated in the last panel. Similar to the monthly maps in Figure 8, the annual means also show higher Chl-a in the small sub-lake in the south and in the astern Poyang Lake. Chl-a was found to be the highest in 2003 and 2004, with a large area showing $>5 \mathrm{mg} \cdot \mathrm{m}^{-3}$ during the two years. To facilitate visualizing the seasonality, as well as inter-annual changes, Figure 10a shows the seasonal mean of Chl-a from 2003 to 2011. Because of the dynamic inundation changes [15], the results were derived from those pixels where $>50 \%$ of the MERIS observations over the inundation area had valid Chl-a retrievals (NGRDI > 0.06). Similar to the 
Chl-a seasonal climatologies in Figure 8, long-term mean Chl-a showed significant seasonality, with higher Chl-a in summer (July to September) than in other seasons. No significant long-term trend was found, however.

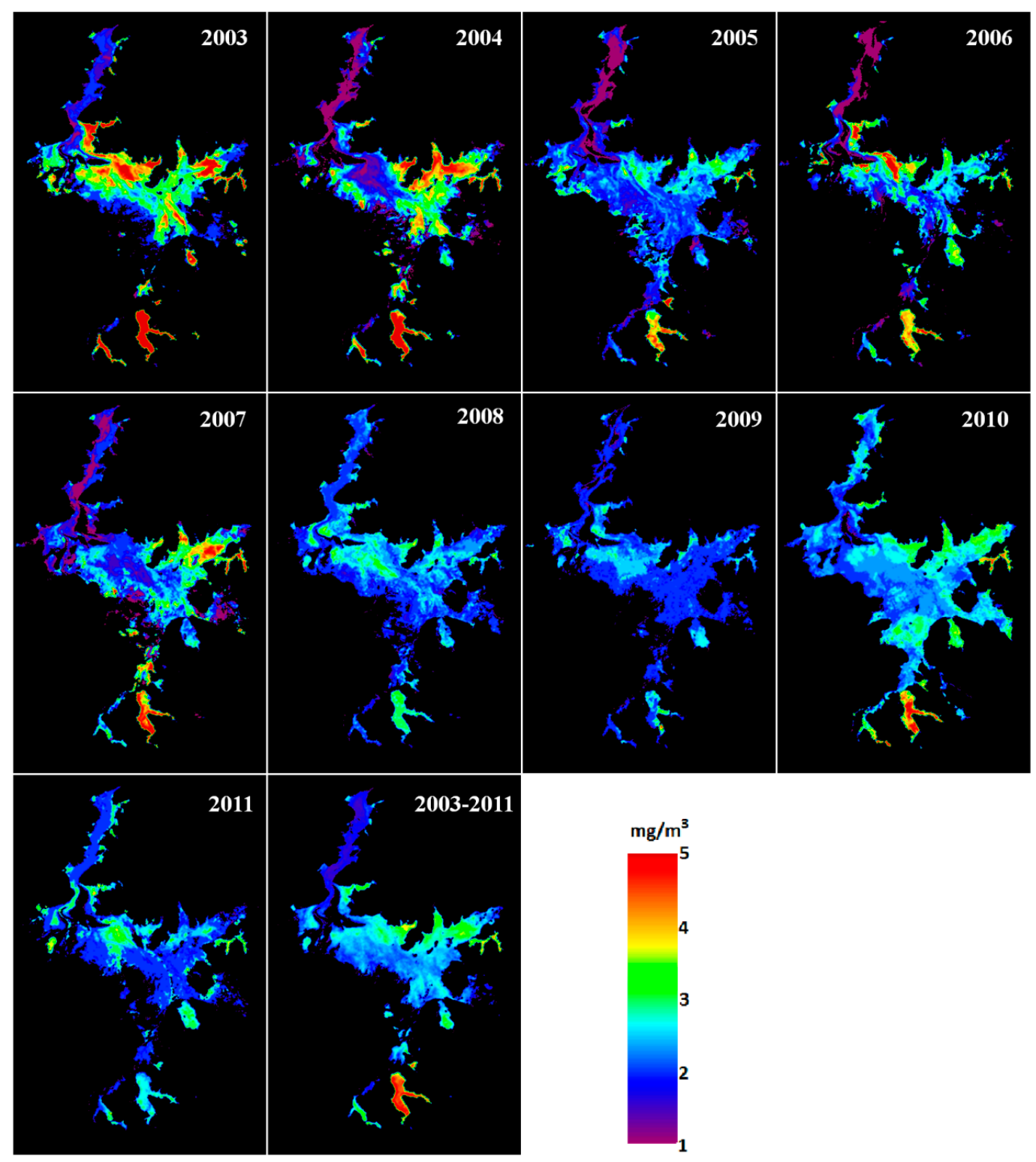

Figure 9. Mean Chl-a distributions of Poyang Lake between July and September, during which the lake inundation and Chl-a reached the maxima) for each year between 2003 and 2011. The last panel shows the summer mean during the nine-year period.

\section{Driving Forces}

The small sub-lake in the south showed much higher Chl-a than any other lake sections during each year. This may be due to the reason that this sub-lake is disconnected from the main lake body, prohibiting water exchanges between them. The eastern lake has similar conditions, where water exchanges are limited by a narrow water channel, as revealed by high spatial resolution images of Google Earth. Thus, the spatial gradient of Chl-a distributions in Poyang Lake is probably linked to water residence time. However, what could cause the significant seasonality? 
Using in situ data from two years, Wu et al. [8] argued that phytoplankton biomass increased with elevated water transparency. To test this hypothesis, long-term seasonal mean Chl-a was correlated to seasonal mean TSS, with the latter derived from MODIS using a regionally-tuned TSS algorithm [6]. For consistency, the seasonal mean Chl-a and TSS were estimated using the same pixels, where $>50 \%$ of valid Chl-a retrievals (NGRDI >0.06) were obtained from the 325 MERIS scenes. A negative correlation was found between Chl-a and TSS $\left(R^{2}=0.19, p<0.05\right.$, Figure 10b), suggesting the potential role of turbidity in regulating underwater light transmission and photosynthesis of Poyang Lake. Indeed, Feng et al. [6,28] have demonstrated that the TSS concentration of Poyang Lake in the dry seasons is about two times as much as in the wet seasons, thus limiting light transmission and possibly phytoplankton growth in the dry seasons.

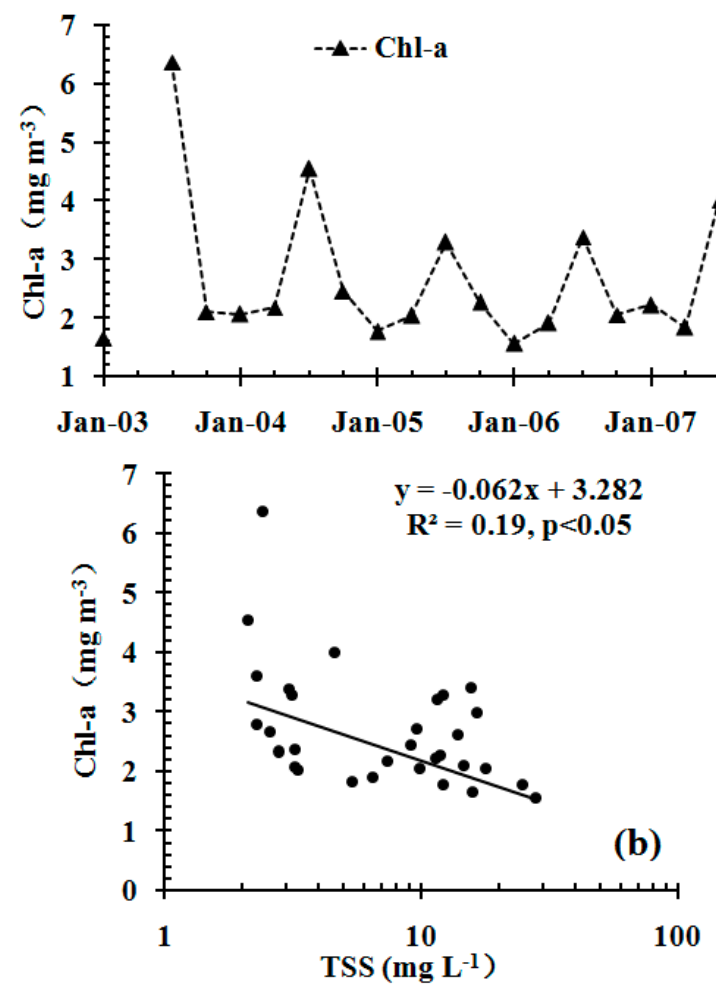

(a)
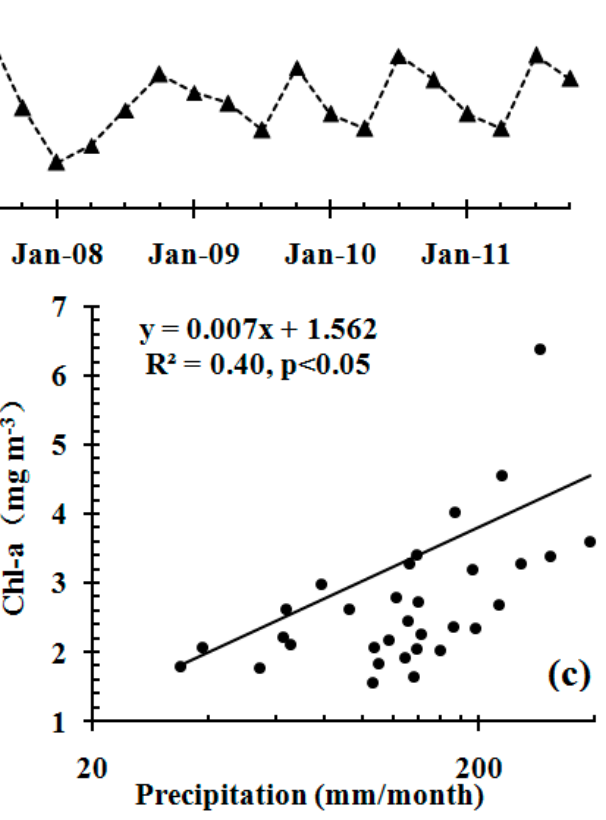

Figure 10. (a) Seasonal mean Chl-a of Poyang Lake from 2003 to 2011. Some of the missing data were due to a lack of cloud-free MERIS images in that season. (b) Correlation between seasonal Chl-a and TSS. (c) Correlation between seasonal Chl-a (with a temporal lag of one season) and precipitation.

In addition, the seasonal variability of hydrological conditions in Poyang Lake may serve as another factor affecting Chl-a, as shown by the statistically-significant correlation $\left(R^{2}=0.40, p<0.05\right.$, Figure 10c) between the seasonal precipitation of the Poyang drainage basin and Chl-a (with a lag of one season). In the dry seasons, when precipitation is low, Poyang Lake shrinks into a narrow water channel with a high south-north water-level gradient [49]. The swift water flow due to the high gradient led to shorter water residence time in non-summer months than in high-precipitation months when the south-north water flow was impeded by the high water level of the Yangtze River. Indeed, the roles of TSS and local precipitation on affecting Poyang Lake's Chl-a were further revealed by their significant correlations at a monthly scale when monthly climatology was considered (Figure 11). 
The availability of ambient nutrients is another factor controlling phytoplankton growth [50,51]. Previous studies showed that concentrations of nutrients (nitrogen and phosphorous) in Poyang Lake are much lower in the wet seasons than in the dry seasons [4,19]. However, such seasonal changes in nutrient concentrations appear to have played a minor role in modulating MERIS Chl-a changes, as their seasonalities are not in phase. However, this result is based on the current conditions in Poyang Lake.

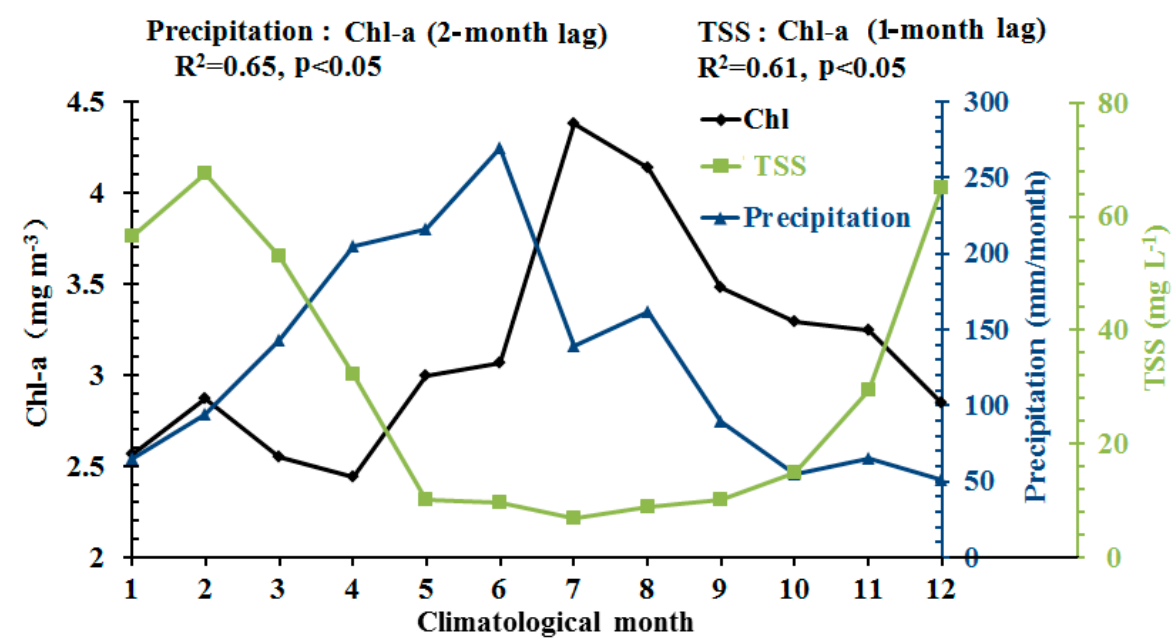

Figure 11. Mean Chl-a of each climatological month during 2003 and 2011. Also plotted are the mean TSS of Poyang Lake and the mean precipitation of the lake's drainage basin. Chl-a with a one month lag showed a statistically-significant negative correlation with TSS and with a two-month lag showed a statistically-significant positive correlation with precipitation.

\section{Discussion}

\subsection{Validity of the Algorithm}

Despite recent advances in both technology and algorithm development, as well as increased remote sensing efforts in monitoring the water quality of inland waters, estimating Chl-a in turbid lakes from satellite measurements is still a technical challenge to the community. For the case of Poyang Lake, the situation is further complicated by its extremely dynamic inundation seasonality and high spatial gradient in water turbidity, making all existing atmospheric correction and bio-optical inversion algorithms questionable. Indeed, tests of the community-accepted Chl-a retrieval algorithms established for other lakes or estuaries using NIR-red-green bands [34,35,52,53] showed non-satisfactory performance (e.g., Figure 5c,d), and existing atmospheric correction embedded in SeaDAS led to negative $R_{\mathrm{rs}}$ for non-masked water pixels. Likewise, plug-in algorithms in the BEAM software [46] also resulted in erroneous $\mathrm{R}_{\mathrm{rs}}$ and invalid Chl-a distributions, as compared to previous studies and field surveys. These problems encouraged us to develop alternative approaches in both atmospheric correction and Chl-a retrievals.

The approach developed in this study to overcome the above difficulties included two steps: (1) a site-specific empirical Chl-a algorithm to account for high turbidity; (2) the use of partially-corrected MERIS $R_{r c}$ instead of fully-corrected MERIS $R_{r s}$ in the Chl-a algorithm, where the additional uncertainties introduced by the use of $\mathrm{R}_{\mathrm{rc}}$ were estimated through radiative transfer simulations. In the absence of validated 
atmospheric correction and bio-optical inversion algorithms to explicitly account for all constituents in water, the empirical approach appears to have worked well in deriving spatial and temporal Chl-a patterns in the dynamic Poyang Lake.

Ideally, an algorithm should be validated using concurrent satellite and field observations that are independent from those used in the algorithm development. However, due to frequent cloud cover, no strictly concurrent (i.e., same day) satellite and field data were available. Therefore, three alternative approaches were used to validate the MERIS-derived Chl-a using the NGRDI algorithm. The first is a temporal consistency check together with visual inspection of the validity of spatial distributions. The second is validation using data that are not strictly concurrent. The third is the above-mentioned LOOCV.

A consistency check was first used to examine the validity of the derived Chl-a spatial distribution patterns and their temporal changes. Chl-a should be higher in the southern lake, including the five tributaries than in the northern lake, where the high concentrations of sediments prevent phytoplankton growth $[6,28]$. Furthermore, except for the five tributaries, Chl-a in the southern lake should not change abruptly with significant patchiness, due to the lack of a point source of nutrients. The field measurements of Chl-a all showed these spatial characteristics. The MERIS NGRDI Chl-a shows spatial patterns that are consistent with these field-based observations, indicating that the NGRDI algorithm could at least derive the relative Chl-a distribution patterns. Furthermore, without a point source of nutrients, Chl-a should change slowly in time (i.e., Chl-a should not jump in adjacent days despite the different atmospheric conditions). Such a rule has been used in Hu et al. [9] to compare Chl-a retrieval algorithms and can also be applied here. Indeed, MERIS Chl-a patterns in adjacent days did not show any sudden changes even under different aerosol influence (as visualized through the RGB images), suggesting that the derived Chl-a patterns were temporally consistent.

Second, a limited validation was performed using near-concurrent MERIS and field measurements. Due to frequent cloud cover and the relatively narrow swath of MERIS, only one MERIS image on 24 July 2011, was found to be close to field surveys (one day after the July, 2011, survey). Figure 12a shows the comparison between MERIS Chl-a on 24 July 2011, and field-measured Chl-a during 15-23 July 2011. As a comparison, MERIS Chl-a derived using the plug-in algorithms in the BEAM software [46] and the three-band algorithm ([35], with BEAM-retrieved $R_{\mathrm{rs}}$ as the algorithm input) were also compared with the field data in Figure $12 \mathrm{~b}, \mathrm{c}$, respectively. The corresponding scatter plots are shown in Figure 13. Both the BEAM plug-in algorithms and the three-band algorithm tended to overestimate Chl-a concentration, as judged by the spatial distribution patterns (Figure 12) and their magnitudes (Figure 13). In contrast, Chl-a derived with the new NGRDI algorithm showed improved agreement with the field measurements. Note that the small difference between the MERIS NGRDI Chl-a and field-measured Chl-a could be a result of different sample sizes and the temporal difference between field and MERIS measurements. 

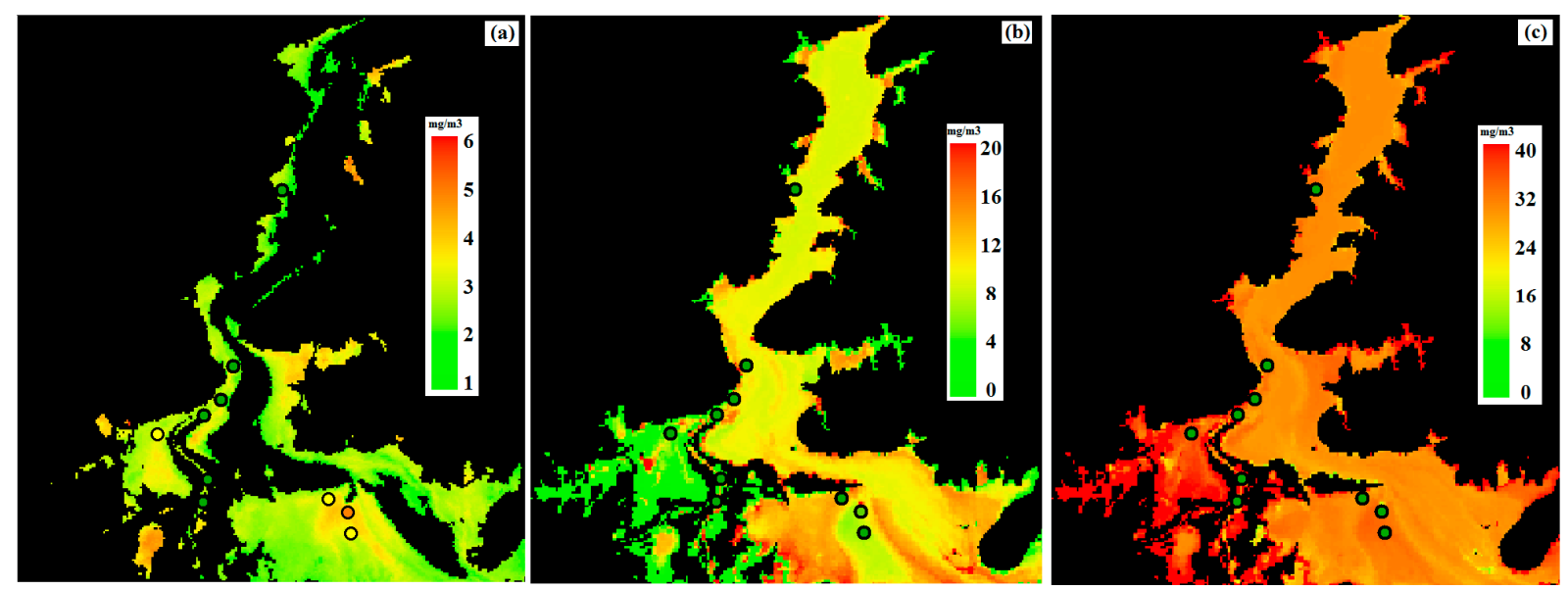

Figure 12. Comparison between field-determined Chl-a (color coded circles) and MERIS-derived Chl-a using different algorithms. MERIS data were collected on 24 July 2011, while field data were collected during 15-23 July 2011. Note the different color scales in the three panels. (a) The NGRDI algorithm proposed in this study; (b) the BEAM plug-in algorithm [46]; (c) the three-band algorithm [35] with BEAM-derived $R_{\mathrm{rs}}$ as the algorithm input. In each panel, the in situ- and remote sensing-derived Chl-a values share the same color coding so that a visual comparison is possible.

Third, the LOOCV analysis also showed acceptable uncertainties in Chl-a estimates, with both the MRE and RMSE being $<40 \%$. The additional $5 \%$ uncertainty introduced by the use of $R_{r c}$ instead of $R_{r s}$, after algorithm adjustment by a factor of 1.25 (Equation (7)), would lead to overall uncertainties of $<45 \%$ in the Chl-a estimates. These uncertainties are lower than the $50 \%-60 \%(\sim 0.2$ in log scale $)$ uncertainties of SeaWiFS-derived Chl-a over the global oceans [38]. Thus, the performance of the empirical NGRDI Chl-a algorithm of Poyang Lake should be regarded as valid. Whether the approach can be extended to other turbid lakes, however, still remains to be tested. Note that the uncertainties presented and discussed here represent random differences of individual data points instead of systematic bias between measured and estimated Chl-a. On monthly scales when many pixels are averaged, the difference between the monthly mean Chl-a derived from MERIS and from water samples (currently such systematic field measurements are not available) would be much smaller.

From its design, the NGRDI Chl-a algorithm is not applicable to the sediment-dominated regions (TSS $>5 \mathrm{mg} \cdot \mathrm{L}^{-1}$ ) of Poyang Lake, and for the same reason, it is not applicable to lakes where TSS is greater than $25 \mathrm{mg} \cdot \mathrm{L}^{-1}$. Feng et al. [28] showed that the mean TSS of the south lake (the main lake body) was generally between $10 \sim 20 \mathrm{mg} \cdot \mathrm{L}^{-1}$ from 2000 to 2010 , where the NGRDI Chl-a algorithm should be valid. In the north lake, TSS could reach $>100 \mathrm{mg} \cdot \mathrm{L}^{-1}$, due to sand dredging activities, and these regions were masked in our analysis. Although Chl-a retrieval is currently not possible for these regions, the negative TSS-Chl-a correlation indicates that Chl-a in these sediment-dominated regions would be low, with a low possibility of eutrophication if Chl-a were used as an index. Therefore, Chl-a dynamics and the eutrophication conditions of Poyang Lake derived in this study should be valid. 

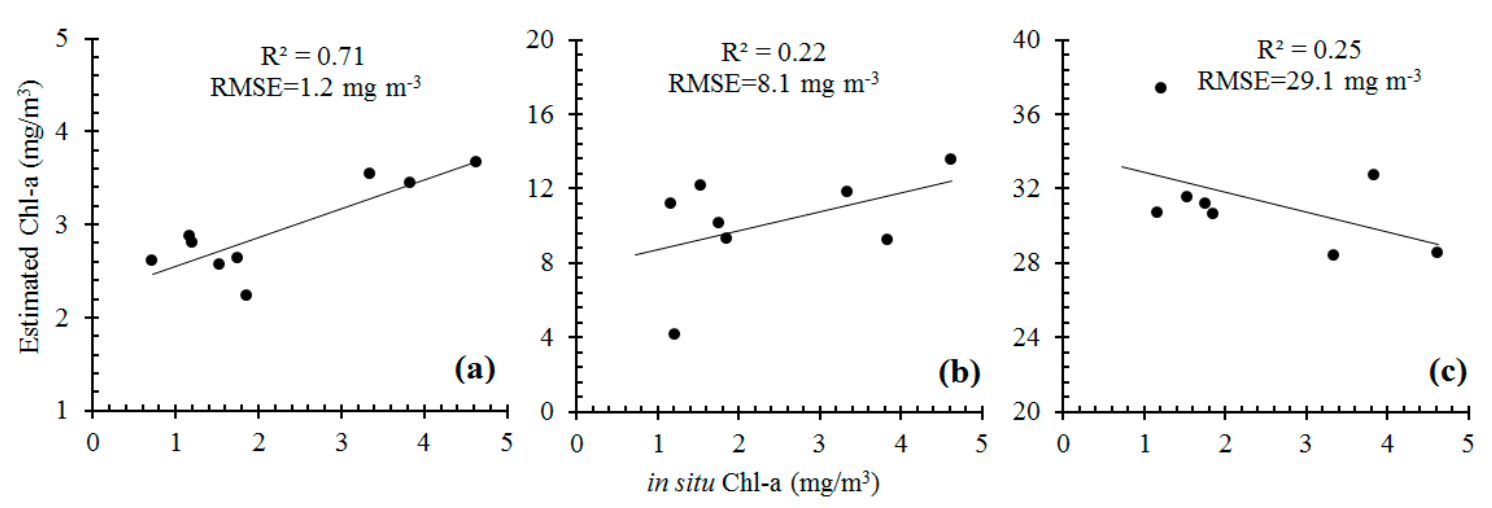

Figure 13. Comparison between field-determined Chl-a and MERIS-derived Chl-a using different algorithms. These scatter plots correspond to the three panels in Figure 12. (a) The NGRDI algorithm proposed in this study; (b) the BEAM plug-in algorithm [46];

(c) the three-band algorithm [35] with BEAM-derived $R_{\mathrm{rs}}$ as the algorithm input.

\subsection{Implications for Future Water Quality Management}

Although MERIS has stopped functioning since April 2012, the established 2003-2012 Chl-a EDR for Poyang Lake still provides useful information to help implement water quality assessment and management plans. The 10-year Chl-a EDR could be used to delineate regions of potential eutrophication, as shown in Figure 14. The statistics show the locations with Chl-a $>10 \mathrm{mg} \cdot \mathrm{m}^{-3} \mathrm{observed}$ at least once during the 10-year period, where the color-coded value represents the occurrence frequency of Chl-a $>10 \mathrm{mg} \cdot \mathrm{m}^{-3}$ during the summer. The total area of the color-shaded regions is $546.4 \mathrm{~km}^{2}$, representing $\sim 15 \%$ of the lake size. Although no sign of eutrophication was found in most regions of Poyang Lake, $>10 \%$ of the MERIS observations showed eutrophic waters $\left(\mathrm{Chl}-\mathrm{a}>10 \mathrm{mg} \cdot \mathrm{m}^{-3}\right)$ in the small sub-lake in the south and in a large portion of the east lake. Therefore, local management effort should be dedicated to these delineated regions to monitor changes in their eutrophication status.

Although, at present, nutrients released from the Poyang Lake drainage basin were not found to correlate with the Chl-a in the lake, when excessive nutrients are released in the future from the continuously growing industry and agriculture around the lake's drainage basin, nutrient concentrations in the lake might exceed a certain threshold, leading to frequent algal blooms during the wet seasons (e.g., the case of Taihu Lake; [54,55]). It is thus necessary to implement a systematic, sustainable water quality monitoring program to assess the lake's eutrophic state, as well as its controlling mechanisms in the future.

It has been shown that the most recently launched Visible Infrared Imager Radiometer Suite (VIIRS) instrument on the Suomi National Polar-orbiting Partnership (SNPP) satellite (October 2011-present) could provide consistent Chl-a estimates for Tampa Bay [56]. VIIRS may provide data continuity for Poyang Lake, as it is equipped with red and green bands similar to those of MERIS, although data quality and algorithm validity need to be evaluated. The ESA has also planned to launch the Ocean and Land Colour Instrument (OLCI) in 2014 [57], whose band setting is similar to MERIS. After sensor-specific Chl-a algorithms are developed in the future from either fully-corrected $R_{r s}$ or partially-corrected $R_{r c}$ to take into account the differences in band positions and bandwidths, as well as in radiometric calibrations, the VIIRS and OLCI data are expected to complement the MERIS products and to form a longer Chl-a EDR for Poyang Lake. 


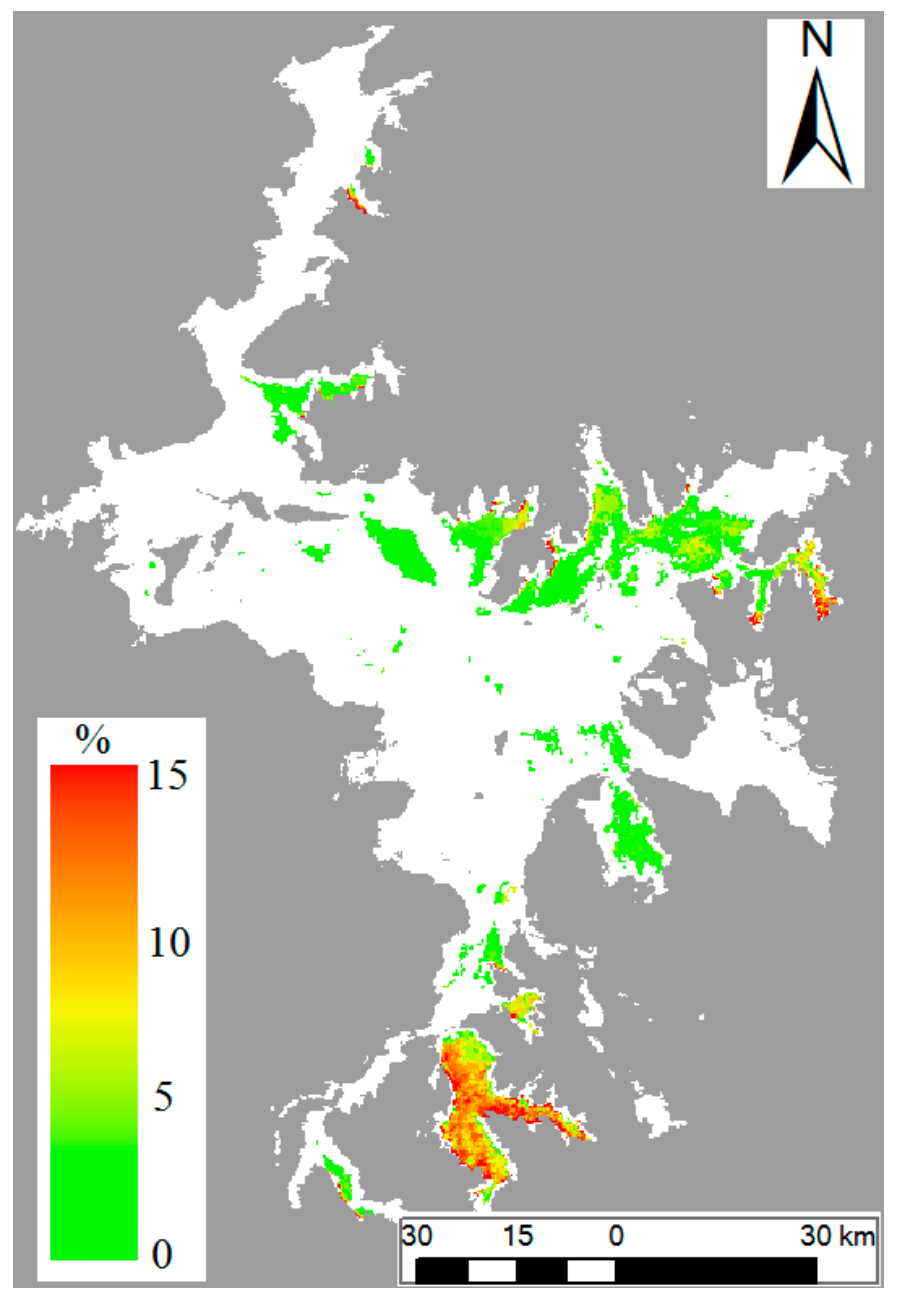

Figure 14. Occurrence frequency of high Chl-a $\left(>10 \mathrm{mg} \cdot \mathrm{m}^{-3}\right)$ between July and September of 2003-2011 from MERIS observations.

\section{Summary and Conclusions}

A regional remote sensing approach has been developed to retrieve Chl-a concentrations from MERIS measurements over Poyang Lake, where the high water turbidity and rapid inundation changes bring additional difficulties to traditional remote sensing approaches. The empirical approach is based on a normalized green-red difference index (NGRDI) derived from MERIS Rayleigh-corrected reflectance at 560 and $681 \mathrm{~nm}$, with an overall algorithm uncertainty of $<45 \%$. This uncertainty estimate includes those originating from the aerosol perturbations ( $\sim 5 \%)$. Based on MERIS observations from 2003 to 2012, spatial and temporal changes of Chl-a in Poyang Lake were documented. Higher Chl-a was observed in summer compared to other seasons. Although Poyang Lake showed an oligotrophic status in most of the lake regions, eutrophic waters $\left(\mathrm{Chl}-\mathrm{a}>10 \mathrm{mg} \cdot \mathrm{m}^{-3}\right)$ were identified in the southern and eastern lake segments.

The study not only provided a practical remote sensing approach to estimate Chl-a in the optically complex Poyang Lake, but also established a 10-year Chl-a EDR for the lake, which may serve as crucial baseline information to monitor and prevent eutrophication in Poyang Lake. Future efforts may extend the approach to other satellite sensors (MODIS, VIIRS, OLCI) in order to develop a seamless Chl-a EDR for Poyang Lake and for other inland or coastal turbid waters, to test its general applicability. 


\section{Acknowledgements}

This work was supported by the National Natural Science Foundation of China (Nos: 41401388 and 41331174), the Major Science and Technology Program for Water Pollution Control and Treatment (2013ZX07105-005), the Fundamental Research Funds for the Central Universities, the Key Laboratory of Poyang Lake Wetland and Watershed Research (Jiangxi Normal University), Ministry of Education (No: JXS-EW-00) and the University of South Florida. We thank U.S. NASA for providing MERIS and TRMM data, and we thank the three anonymous reviewers for their comments. We are indebted to several local environmental agencies and groups who collected and provided surface runoff and rain gauge data.

\section{Author Contributions}

Lian Feng came up with the algorithm idea and prepared the manuscript draft; Chuanmin $\mathrm{Hu}$ processed MERIS data and together with Xiaoling Chen helped to outline the manuscript structure; Xingxing Han and Lin Qi analyzed and diagnosed the field and satellite data.

\section{Conflicts of Interest}

The authors declare no conflict of interest.

\section{References}

1. Fang, J.; Rao, S.; Zhao, S. Human-induced long-term changes in the lakes of the Jianghan plain, central Yangtze. Front. Ecol. Environ. 2005, 3, 186-192.

2. Yang, G.; Ma, R.; Zhang, L.; Jiang, J.; Wei, S.; Zhang, M.; Zeng, H. Lake status, major problems and protection strategy in China. J. Lake Sci. 2010, 22, 799-810.

3. Yin, L.; Jiang, N.; Yang, Y. Dynamic change of Lake Taihu area during the past 15 years based on remote sensing technique. J. Lake Sci. 2005, 17, 139-142.

4. Hu, C.; Zhou, W.; Wang, M.; Wei, Z. Inorganic nitrogen and phosphate and potential eutrophication assessment in Lake Poyang. J. Lake Sci. 2010, 22, 723-728.

5. Shang, G.P.; Shang, J.C. Causes and control countermeasures of eutrophication in Chaohu Lake, China. Chin. Geogr. Sci. 2005, 15, 348-354.

6. Feng, L.; Hu, C.; Chen, X.; Zhao, X. Dramatic inundation changes of China's two largest freshwater lakes linked to the Three Gorges Dam. Environ. Sci. Technol. 2013, 47, 9628-9634.

7. Wu, G.; Leeuw, J.D.; Skidmore, A.K.; Prins, H.H.T.; Liuc, Y. Concurrent monitoring of vessels and water turbidity enhances the strength of evidence in remotely sensed dredging impact assessment. Water Res. 2007, 41, 3272-3280.

8. Wu, Z.; Cai, Y.; Liu, X.; Xu, C.P.; Chen, Y.; Zhang, L. Temporal and spatial variability of phytoplankton in Lake Poyang: The largest freshwater lake in China. J. Great Lakes Res. 2013, 39, 476-483.

9. Hu, C.; Feng, L.; Lee, Z.; Davis, C.O.; Mannino, A.; McClain, C.R.; Franz, B.A. Dynamic range and sensitivity requirements of satellite ocean color sensors: Learning from the past. Appl. Opt. 2012 , $51,6045-6062$. 
10. Adam, E.; Mutanga, O.; Rugege, D. Multispectral and hyperspectral remote sensing for identification and mapping of wetland vegetation: A review. Wetl. Ecol. Manag. 2010, 18, 281-296.

11. Ozesmi, S.L.; Bauer, M.E. Satellite remote sensing of wetlands. Wetl. Ecol. Manag. 2002, 10, 381-402.

12. Best, R.; Moore, D. Landsat interpretation of prairie lakes and wetlands of eastern south Dakota. In Proceedings of the Series-American Water Resources Association, New York, NY, USA, 26-27 September 1979.

13. World Lake Database. Available online: Http://wldb.Ilec.Or.Jp/ (accessed on 9 October 2014).

14. Zhang, B. Research of Poyang Lake; Shanghai Scientific \& Technical Publishers: Shanghai, China, 1988.

15. Feng, L.; Hu, C.; Chen, X.; Cai, X.; Tian, L.; Gan, W. Assessment of inundation changes of Poyang Lake using MODIS observations between 2000 and 2010. Remote Sens. Environ. 2012, 121, 80-92.

16. Shankman, D.; Keim, B.D.; Song, J. Flood frequency in China's Poyang Lake region: Trends and teleconnections. Int. J. Climatol. 2006, 26, 1255-1266.

17. Zhong, Y.; Chen, S. Impact of dredging on fish in Poyang Lake. Jiangxi Fish. Sci. Technol. 2005, 1, 15-18. (In Chinese)

18. Zhang, K. Poyang Lake: Saving the Finless Porpoise. Available online: http://www.chinadialogue.org.cn/article/show/single/en/839-Poyang-Lake-saving-the-finless-porpoise (accessed on 9 October 2014).

19. Luo, D.; Wu, X.; Li, S.; Hu, C.; Zhou, W. Investigate study on tp pollution load of Poyang Lake by water and salt balance. J. Lake Sci. 2011, 47, 336-343.

20. A $10 \mathrm{~km}$-Long Cyanobacteria Bloom was Observed in Poyang Lake. Available online: http://www.Pyyou.Com/html/lvyouzixun/20121018/2485.Html (accessed on 9 October 2014). (In Chinese)

21. Gordon, H.R. Atmospheric correction of ocean color imagery in the earth observing system era. J. Geophys. Res. 1997, 102, 17081-17106.

22. Gordon, H.R.; Wang, M. Retrieval of water-leaving radiance and aerosol optical thickness over the oceans with seawifs: A preliminary algorithm. Appl. Opt. 1994, 33, 443-452.

23. Bailey, S.W.; Franz, B.A.; Werdell, P.J. Estimation of near-infrared water-leaving reflectance for satellite ocean color data processing. Opt. Express 2010, 18, 7521-7527.

24. Hooker, S.; Firestone, E.R.; Patt, F.S.; Barnes, R.A.; Eplee, R.E., Jr.; Franz, B.A.; Robinson, W.D.; Feldman, G.C.; Bailey, S.W. Algorithm Updates for the Fourth Seawifs Data Reprocessing. Available online: http://oceancolor.gsfc.nasa.gov/SeaWiFS/TECH_REPORTS/PLVol22.pdf (accessed on 9 October 2014).

25. Qi, L.; Hu, C.; Duan, H.; Cannizzaro, J.; Ma, R. A novel MERIS algorithm to derive cyanobacterial phycocyaninpigment concentrations in a eutrophic lake: Theoretical basis and practical considerations. Remote Sens. Environ. 2014, 154, 298-317.

26. Mobley, C.D. Estimation of the remote-sensing reflectance from above-surface measurements. Appl. Opt. 1999, 38, 7442-7455.

27. Yu, Z.; Chen, X.; Zhou, B.; Tian, L.; Yuan, X.; Feng, L. Assessment of total suspended sediment concentrations in Poyang Lake using HJ-1A/1B CCD imagery. Chin. J. Oceanol. Limnol. 2012, 30, 295-304. 
28. Feng, L.; Hu, C.; Chen, X.; Tian, L.; Chen, L. Human induced turbidity changes in Poyang Lake between 2000 and 2010: Observations from MODIS. J. Geophys. Res. Ocean. (1978-2012) 2012 , 117, doi:10.1029/2011JC007864.

29. Gordon, H.R.; Morel, A.Y. Remote assessment of Ocean Color for Interpretation of Satellite Visible Imagery: A Review; American Geophysical Union: Washington, DC, USA, 1983.

30. Morel, A.; Prieur, L. Analysis of variations in ocean color. Limnol. Oceanogr. 1977, 22, 709-722.

31. Knorn, J.; Rabe, A.; Radeloff, V.C.; Kuemmerle, T.; Kozak, J.; Hostert, P. Land cover mapping of large areas using chain classification of neighboring landsat satellite images. Remote Sens. Environ. 2009, 113, 957-964.

32. Babin, M.; Morel, A.; Fournier-Sicre, V.; Fell, F.; Stramski, D. Light scattering properties of marine particles in coastal and open ocean waters as related to the particle mass concentration. Limnol. Oceanogr. 2003, 48, 843-859.

33. Babin, M.; Stramski, D.; Ferrari, G.M.; Claustre, H.; Bricaud, A.; Obolensky, G.; Hoepffner, N. Variations in the light absorption coefficients of phytoplankton, nonalgal particles, and dissolved organic matter in coastal waters around Europe. J. Geophys. Res. 2003, 108, doi:10.1029/2001JC000882.

34. Gurlin, D.; Gitelson, A.A.; Moses, W.J. Remote estimation of chl- a concentration in turbid productive waters - Return to a simple two-band NIR-red model? Remote Sens. Environ. 2011, 115, 3479-3490.

35. Gitelson, A.A.; Dall'Olmo, G.; Moses, W.; Rundquist, D.C.; Barrow, T.; Fisher, T.R.; Gurlin, D.; Holz, J. A simple semi-analytical model for remote estimation of chlorophyll-a in turbid waters: Validation. Remote Sens. Environ. 2008, 112, 3582-3593.

36. Efron, B. Estimating the error rate of a prediction rule: Improvement on cross-validation. J. Am. Stat. Assoc. 1983, 78, 316-331.

37. Hooker, S.B.; Esaias, W.E.; Feldman, G.C.; Gregg, W.W.; McClain, C.R. An Overview of Seawifs and Ocean Color; National Aeronautics and Space Administration, Goddard Space Flight Center: Greenbelt, MD, USA, 1992.

38. Gregg, W.W.; Casey, N.W. Global and regional evaluation of the seawifs chlorophyll data set. Remote Sens. Environ. 2004, 93, 463-479.

39. Mishra, S.; Mishra, D.R. Normalized difference chlorophyll index: A novel model for remote estimation of chlorophyll-a concentration in turbid productive waters. Remote Sens. Environ. 2012, 117, 394-406.

40. Le, C.; Li, Y.; Zha, Y.; Sun, D.; Huang, C.; Lu, H. A four-band semi-analytical model for estimating chlorophyll a in highly turbid lakes: The case of Taihu Lake, China. Remote Sens. Environ. 2009, 113, 1175-1182.

41. Cheng, C.; Wei, Y.; Lv, G.; Yuan, Z. Remote estimation of chlorophyll-a concentration in turbid water using a spectral index: A case study in Taihu Lake, China. J. Appl. Remote Sens. 2013, 7, doi:10.1117/1.JRS.7.073465.

42. Le, C.; Hu, C.; English, D.; Cannizzaro, J.; Kovach, C. Climate-driven chlorophyll-a changes in a turbid estuary: Observations from satellites and implications for management. Remote Sens. Environ. 2013, 130, 11-24. 
43. Motohka, T.; Nasahara, K.N.; Oguma, H.; Tsuchida, S. Applicability of green-red vegetation index for remote sensing of vegetation phenology. Remote Sens. 2010, 2, 2369-2387.

44. Antoine, D.; Morel, A. A multiple scattering algorithm for atmospheric correction of remotely sensed ocean colour (MERIS instrument): Principle and implementation for atmospheres carrying various aerosols including absorbing ones. Int. J. Remote Sens. 1999, 20, 1875-1916.

45. Wang, M.; Shi, W. The NIR-SWIR combined atmospheric correction approach for MODIS ocean color data processing. Opt. Express 2007, 15, 15722-15733.

46. Doerffer, R.; Schiller, H. The MERIS case 2 water algorithm. Int. J. Remote Sens. 2007, 28, $517-535$.

47. Baith, K.; Lindsay, R.; Fu, G.; McClain, C.R. Data analysis system developed for ocean color satellite sensors. Eos Trans. Am. Geophys. Union 2001, 82, 202-202.

48. Robinson, W.D.; Franz, B.A.; Patt, F.S.; Bailey, S.W.; Werdell, P.J. Masks and Flags Updates. Seawifs Postlaunch Technical Report Series. Available online: http:/oceancolor.gsfc.nasa.gov/ SeaWiFS/TECH_REPORTS/PLVol22.pdf (accessed on 9 October 2014).

49. Feng, L.; Hu, C.; Chen, X.; Li, R.; Tian, L.; Murch, B. MODIS observations of the bottom topography and its inter-annual variability of Poyang Lake. Remote Sens. Environ. 2011, 115, 2729-2741.

50. Seip, K.L. Phosphorus and nitrogen limitation of algal biomass across trophic gradients. Aquat. Sci. 1994, 56, 16-28.

51. Teubner, K.; Dokulil, M.T. Ecological stoichiometry of TN: TP: SRSi in freshwaters: Nutrient ratios and seasonal shifts in phytoplankton assemblages. Arch. Fur Hydrobiol. 2002, 154, 625-646.

52. Gons, H.J.; Rijkeboer, M.; Ruddick, K.G. A chlorophyll-retrieval algorithm for satellite imagery (medium resolution imaging spectrometer) of inland and coastal waters. J. Plankton Res. 2002, 24, 947-951.

53. Moses, W.J.; Gitelson, A.A.; Berdnikov, S.; Saprygin, V.; Povazhnyi, V. Operational MERIS-based nir-red algorithms for estimating chlorophyll-a concentrations in coastal waters-The Azov Sea case study. Remote Sens. Environ. 2012, 121, 118-124.

54. Hu, C.; Lee, Z.; Ma, R.; Yu, K.; Li, D.; Shang, S. Moderate resolution imaging spectroradiometer (MODIS) observations of cyanobacteria blooms in Taihu Lake, China. J. Geophys. Res. 2010, 115, doi:10.1029/2009JC005511

55. Gu., F.; Liu, W. Applications of remote sensing and gis to the assessment of riparian zones for environmental restoration in agricultural watersheds. Geo-Spat. Inf. Sci. 2010, 39, 386-389.

56. Hu, C.; Le, C. Ocean color continuity from VIIRS measurements over Tampa Bay. IEEE Geosci. Remote Sens. Lett. 2014, 11, 945-949.

57. International Ocean Colour Science Meeting 2015. Available online: http://iocs.Ioccg.Org/ wp-content/uploads/1020-henri-laur-esa-from-meris-to-olci.Pdf (accessed on 9 October 2014).

(C) 2014 by the authors; licensee MDPI, Basel, Switzerland. This article is an open access article distributed under the terms and conditions of the Creative Commons Attribution license (http://creativecommons.org/licenses/by/4.0/). 